\title{
Mechanical Behavior and Microstructural Development of Low-Carbon Steel and Microcomposite Steel Reinforcement Bars Deformed under Quasi-Static and Dynamic Shear Loading
}

\author{
L.M. DOUGHERTY, E.K. CERRETA, G.T. GRAY III, C.P. TRUJILLO, M.F. LOPEZ, \\ K.S. VECCHIO, and G.J. KUSINSKI
}

\begin{abstract}
Reinforcement bars of microcomposite (MC) steel, composed of lath martensite and minor amounts of retained austenite, possess improved strength and corrosion characteristics over low-carbon (LC) steel rebar; however, their performance under shear loading has not previously been investigated at the microstructural level. In this study, LC and MC steel cylinders were compression tested, and specimens machined into a forced-shear geometry were subjected to quasi-static and dynamic shear loading to determine their shear behavior as a function of the strain and strain rate. The as-received and sheared microstructures were examined using optical microscopy (OM), scanning electron microscopy (SEM), and electron backscatter diffraction (EBSD). Higher-resolution microstructural examinations were performed using transmission electron microscopy (TEM). The influence of the starting microstructure on the shear behavior was found to depend strongly on the strain rate; the MC steel exhibited not only greater strainrate sensitivity than the LC steel but also a greater resistance to shear localization with load. In both steels, despite differences in the starting microstructure, post-mortem observations were consistent with a continuous mechanism operating within adiabatic shear bands (ASBs), in which subgrains rotated into highly misoriented grains containing a high density of dislocations.
\end{abstract}

DOI: $10.1007 / \mathrm{s} 11661-009-9869-2$

(C) The Author(s) 2009. This article is published with open access at Springerlink.com

\section{INTRODUCTION}

As a construction material, concrete is limited in its structural integrity by its poor tensile properties, despite its exceptional performance in compression. To address this deficiency, materials with good tensile strength and ductility are selected for use as reinforcement bars, frequently concatenated to "rebar," within the concrete. The most common material used in rebar is low-carbon (LC) steel, which is an inexpensive, high-strength ferritic-pearlitic alloy that is easily shaped into the forms necessary to reinforce concrete structures and is easily deformed at the surface, to improve the bond between the concrete and the reinforcement.

As defined by ASTM specifications, rebar is available in three grades that correspond to the three different yield strength values of 280,420 , and $520 \mathrm{MPa} \cdot{ }^{[1]}$ These

L.M. DOUGHERTY, formerly a Postdoctoral Associate with MST-8, Los Alamos National Laboratory, Los Alamos, NM 87545, is an R\&D Engineer with WCM-1, Los Alamos National Laboratory. Contact e-mail: lmdough@lanl.gov E.K. CERRETA and G.T. GRAY III, Staff Scientists, and C.P. TRUJILLO and M.F. LOPEZ, Technicians, are with MST-8, Los Alamos National Laboratory. K.S. VECCHIO, Chair, is with the Nanoengineering Department, University of California at San Diego, San Diego, CA 92093. G.J. KUSINSKI, formerly with the MMFX Technologies Corporation, Irvine, CA 92606, is with the Chevron Energy Technology Company, Richmond, CA 94802-0627.

Manuscript submitted July 30, 2008

Article published online June 16, 2009 grades do not prescribe or regulate the physical characteristics (e.g., phase and microstructure) of the steel; therefore, such characteristics can vary substantially from one manufacturer to another, despite identical strength and ductility performance. Because carbon steels are susceptible to rusting, a corrosion process that expands the volume of reinforcements and leads to cracking of the concrete and eventual failure of the structures, materials that offer greater corrosion resistance than LC steel have been developed for rebar applications in corrosive environments. To account for these engineered materials, additional specifications that include corrosion tests and corrosion resistance requirements have been approved by ASTM. Stainless steel ${ }^{[2]}$ and epoxy-coated steel ${ }^{[3]}$ provide corrosion resistance without sacrificing strength, but these materials can be costly. Fiber-reinforced polymer composites are used on a limited basis in bridge decks and industrial applications, but are even more costly, exhibit inferior stiffness compared to steel reinforcements, and are susceptible to environmental degradation. ${ }^{[4]}$

Recently, a less costly option for corrosion-resistant concrete reinforcement bars was approved by ASTM; in this option, corrosion resistance was achieved in a twophase steel by lowering the carbon content to $0.15 \mathrm{wt}$ pct or less and introducing up to $1.5 \mathrm{wt} \mathrm{pct}$ manganese and 8.0 to $10.9 \mathrm{wt}$ pct chromium (which is less than the minimum content of $12 \mathrm{wt}$ pct chromium in typical stainless steels). ${ }^{[5,6]}$ In addition, the strength 
was improved over mild steel through thermomechanical processing to produce a "microcomposite" (MC) microstructure of lath martensite with a thin film of retained austenite between laths. ${ }^{[7]}$ The characteristics and performance of this MC steel were defined in a new ASTM specification for a chromium-containing reinforcement steel that included a fourth grade of rebar corresponding to a yield strength of $690 \mathrm{MPa}$. In 2007, this specification was expanded to include another grade of rebar corresponding to a yield strength of $830 \mathrm{MPa}{ }^{[8]}$

Because reinforced concrete structures may be subjected to shear stress, e.g., in the event of an earthquake, high winds, or impact, the reinforcement bar performance under shear loading is of interest. Compounding this problem, concrete under shear stress may crack, resulting in the concentration of the shear load onto a relatively small, confined region of a reinforcement bar. As such, resistance of the microstructure to shear band formation, which is a common precursor to fracture, is desirable in order to prevent the catastrophic failure of a reinforced concrete structure. Although specific investigations into the shear behavior of rebar are few, ${ }^{[9]}$ research concerning the shear behavior, particularly the formation and evolution of adiabatic shear bands (ASBs), of alloys similar to those used in rebar is extensive.

The microstructures of metals subjected to rapid and intense shear loading may become unstable, at which point they are susceptible to the formation of ASBs. These are regions of intense deformation surrounded by regions that are, for the most part, unaffected by the applied stress. This variation in shear deformation is the result of restricted thermal conductivity due to the high rate of loading. Thus, the process of shear band formation is considered adiabatic, where "hot" spots develop adjacent to "cold" spots in the region subjected to shear stress. These hot spots exhibit greater ductility than the cold spots, resulting in confined zones, or bands, of very high deformation. The factors responsible for the formation and evolution of ASBs remain under discussion; however, a number of theories based on the results of investigations of various metals and alloys have been developed to explain the mechanisms operating during shear localization and shear band formation.

Microstructural instability can be exacerbated by the existence of a complex phase structure (e.g., cementite plates in ferrite, in which the interfaces between the phases may function as profuse dislocation sources when subjected to shear stress $)^{[10]}$ or by extensive defect generation and storage (e.g., impact loading). ${ }^{[11,12]}$ In both cases, the migration of dislocations, a mechanism to accommodate deformation, is restricted by mobility barriers, forcing deformation to concentrate as dislocation pileups in localized regions. At large strains, these pileups can avalanche, thereby initiating the formation of ASBs. ${ }^{[13]}$ Once shear bands form, the strain to failure of the specimen or component is much less than would be achievable if the deformation were distributed over a wider region.

In the past, microstructural examinations within ASBs have been performed primarily using optical microscopy (OM) and scanning electron microscopy (SEM) along with the judicious use of transmission electron microscopy (TEM), to resolve fine microstructural features. ${ }^{[14-18]}$ More recently, electron backscatter diffraction (EBSD) has been employed to determine texture and boundary misorientation distributions within ASBs. ${ }^{[19-22]}$ To date, most EBSD texture studies of shear deformation in metals and alloys have concentrated on fcc crystal structures, ${ }^{[23,24]}$ relatively few have concentrated on bcc crystal structures. ${ }^{[21,25]}$ Of particular interest in these studies was the development of an understanding of the transition between strain localization and ASB formation. Focused ion beam (FIB) extraction has proven useful in the microstructural characterization of ASBs by enabling the accurate removal of TEM specimens from precise locations near or within ASBs, to more closely examine specific features observed with the SEM. ${ }^{[22,26]}$

The dominant mechanism driving microstructural changes within ASBs during the shear deformation of metals and alloys is unclear and a number of different mechanisms have been proposed. These include dynamic recovery, ${ }^{[27,28]}$ dynamic recrystallization, ${ }^{[12,21,29-32]}$ strain-induced phase transformation, ${ }^{[33,34]}$ amorphization, ${ }^{[20,35]}$ and carbon segregation. ${ }^{[15]}$ The strain-induced phase transformation mechanism has been challenged by researchers who claim that evidence for a phase transformation in ASBs has not been provided ${ }^{[28]}$ and that, even if one did occur, it would be of secondary importance to another mechanism. ${ }^{[36]}$ Carbon segregation to ASBs is also unlikely to be a dominating mechanism because, even though this mechanism can explain higher hardnesses in ASBs than in surrounding microstructures in iron-carbon alloys, it cannot explain the enhanced hardness of ASBs in non-carbon-containing alloys. Therefore, the mechanisms that most likely dominate during the evolution of ASB microstructures during shear deformation are dynamic recovery and dynamic recrystallization. Because no single mechanism has been proven to control the microstructural evolution in the ASBs of all metals and alloys, however, the operative mechanism most likely varies from material to material, depending on the deformation conditions, microstructural characteristics, and phase and chemical composition of the specific metal or alloy involved.

In steels, the determination of the primary mechanism controlling the microstructural evolution in ASBs during shear deformation is complicated by the intricacies of the iron-carbon system. Microstructures are frequently comprised of multiple phases that vary widely in structure and distribution, depending on thermomechanical processing parameters and the presence of minor chemical constituents. For example, Xue et al. ${ }^{[37,38]}$ studied ASB formation and evolution in a stainless steel, using TEM to show the substructure across the entire ASB width. They determined that both dynamic recovery and continuous dynamic recrystallization occurred inside the ASBs during high-rate shear deformation. In a recent study of an interstitial-free steel, Lins et al. ${ }^{[21]}$ claimed that "progressive subgrain misorientation" (PriSM) recrystallization, originally proposed by Hines et al., ${ }^{32]}$ was the mechanism responsible for the development of the ultrafine-grained structure within ASBs. Alternatively, Lesuer et al. ${ }^{[33]}$ 
concluded after his investigation of high-rate shear in an ultrahigh-carbon steel that, within the sheared region, a "divorced eutectoid transformation" occurred, in which the ferrite in the pearlite transformed instantaneously to austenite, while the cementite broke into finely dispersed nanocarbides and then the austenite rapidly retransformed into fine, carbide-containing ferrite grains.

The purpose of the current research is to compare, at the microstructural level, the shear performance of $\mathrm{MC}$ and LC steels, two alloys that are currently in use in concrete reinforcement bars. This information can then be used to better understand the microstructural mechanisms operating during localized shear deformation in these steels. Of particular interest is whether the primary mechanisms controlling the microstructural development within the ASBs in both steels are the same. Tests were performed using a range of strain rates, with the greatest emphasis on the rates above $1000 / \mathrm{s}$, in order to determine the impact of the starting microstructure on ASB formation and evolution. Possible factors instigating a transition from shear localization (in which the original microstructure is still identifiable, although severely deformed) to shear band formation (in which the original microstructure has been completely replaced by a new microstructure) observed to occur in the $\mathrm{MC}$ steel but not in the LC steel at the rates tested were considered. Using the results of this study, the propensity for shear band formation in these steels as a function of the starting microstructure, strain rate, and peak load was discussed.

\section{EXPERIMENT}

Bars of commercial reinforcement steel (15.9-mm diameter, grade 420, per ASTM specification A615/ A615/M-07) and MMFX-9Cr steel (19.1-mm diameter, grade 690, per ASTM specification A1035/A1035M-07) were sectioned for experimental study. The commercial reinforcement bar was $\mathrm{LC}$ steel with a maximum carbon content of $0.3 \mathrm{wt}$ pct. The MMFX steel (MMFX Technologies Corporation, Irvine, CA) was an $\mathrm{MC}$ steel conforming to the following specification requirements for composition in terms of maximum weight percent (except where a range is specified): 0.15 carbon, 8.0 to 10.9 chromium, 1.5 manganese, 0.05 nitrogen, 0.035 phosphorus, 0.045 sulfur, and 0.50 silicon.

Right-regular compression cylinders and hat-shaped specimens were cut from the two types of reinforcement steel in both the transverse (T) direction and longitudinal (L) direction, as defined in Figure 1. The geometry of the hat-shaped specimens ${ }^{[38]}$ was designed so as to force shear to occur in a predefined region. Quasi-static compression tests on the two types of rebar steel, performed at a strain rate of $0.001 / \mathrm{s}$, was used to define their mechanical behavior under uniaxial loading. The compression test results for the MC steel correlated well with the compression data ${ }^{[9]}$ and tensile data ${ }^{[39]}$ from tests performed previously on the same material by other organizations.

The hat-shaped LC and MC steel specimens were subjected to shear testing at strain rates of $0.001 / \mathrm{s}$ and

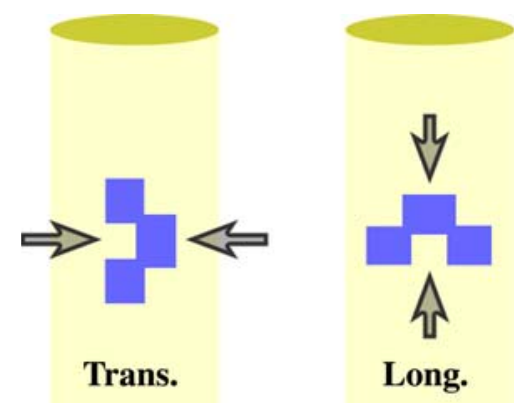

Fig. 1-Depiction of $\mathrm{T}$ and $\mathrm{L}$ specimen orientations in relation to the geometry of the concrete reinforcement bars. The arrows indicate loading direction during quasi-static and dynamic shear testing of hat-shaped specimens.

0.1/s in an Instron* Model 1125 electromechanical test

*Instron is a trademark of Illinois Tool Works (ITW), Inc., Glenview, IL.

system. Dynamic shear tests were performed in a splitHopkinson pressure bar (SHPB) apparatus at strain rates, applied to the specimen normal, of $1600 / \mathrm{s}, 1800 / \mathrm{s}$, $2500 / \mathrm{s}, 2800 / \mathrm{s}$, and $2900 / \mathrm{s}$ on L specimens of the LC steel; $1700 /$ s, $2300 /$ s, $4900 /$ s, and $5200 /$ s on T specimens of the LC steel; 600/s, 900/s, 950/s, 1900/s, 2800/s, and $2900 /$ s on L specimens of the MC steel; and $1200 / \mathrm{s}$, $1800 / \mathrm{s}$, and $2500 / \mathrm{s}$ on $\mathrm{T}$ specimens of the MC steel. All tested specimens and test data are listed in Table I. The engineering-shear-stress- $v s$-displacement curves for all LC steel specimens are plotted in Figure 2(a). The curves for the MC steel specimens are plotted in Figure 2(b).

In these tests, engineering shear stress was calculated using the initial gage height, the hat and hole diameters (the difference of which roughly defines the width of the shear-affected zone), and the specimen height. These parameters are defined in the two-dimensional schematic of a bisected hat-shaped specimen shown in Figure 3. Due to the geometry of these specimens, only the change in gage length is known during dynamic shear testing. It is not possible to know in situ the change in the width of the shear-affected zone, so it is not possible to calculate the true shear stress as a function of the change in gage length. Consequently, engineering shear stress rather than true shear stress was used as the dependent variable in all plots from the SHPB tests. Likewise, without knowing the change in the width of the ASBs with the change in gage length, true shear strains could not be calculated. Therefore, displacement, expressed in millimeters, rather than true shear strain was used as the independent variable.

Comparison of the engineering-shear-stress- $v s$-displacement curves from compression tests at $0.001 / \mathrm{s}$ on $\mathrm{L}$ and $\mathrm{T}$ specimens from both types of rebar steel, as shown in Figure 4, indicates that shear behavior is independent of specimen orientation in both the LC and $\mathrm{MC}$ steels. Because of this, the $\mathrm{L}$ and $\mathrm{T}$ orientations 
Table I. All Specimens Tested in Shear Using Either an Instron Electromechanical Test System (Strain Rates 0.1/s and $0.001 / \mathrm{s}$ ) or an SHPB Apparatus (All Other Strain Rates)

\begin{tabular}{|c|c|c|c|c|}
\hline Designation & $\begin{array}{c}\text { Type of } \\
\text { Rebar } \\
\text { Steel }\end{array}$ & Orientation & $\begin{array}{c}\text { Strain } \\
\text { Rate }(/ \mathrm{s})\end{array}$ & $\begin{array}{c}\text { Final } \\
\text { Displacement } \\
(\mathrm{mm})\end{array}$ \\
\hline LC-L\#0 & $\mathrm{LC}$ & $\mathrm{L}$ & 0.001 & 0.62 \\
\hline LC-L\#1 & $\mathrm{LC}$ & $\mathrm{L}$ & 1800 & 0.38 \\
\hline LC-L\#2 & $\mathrm{LC}$ & $\mathrm{L}$ & 2500 & 0.55 \\
\hline LC-L\#3 & $\mathrm{LC}$ & $\mathrm{L}$ & 1600 & 0.33 \\
\hline LC-L\#4 & $\mathrm{LC}$ & $\mathrm{L}$ & 2900 & 0.47 \\
\hline LC-L\#5 & $\mathrm{LC}$ & $\mathrm{L}$ & 2900 & 0.46 \\
\hline LC-L\#7 & $\mathrm{LC}$ & $\mathrm{L}$ & 2800 & 0.45 \\
\hline LC-T\#0 & $\mathrm{LC}$ & $\mathrm{T}$ & 0.001 & 0.62 \\
\hline LC-T\#1 & $\mathrm{LC}$ & $\mathrm{T}$ & 1700 & 0.36 \\
\hline LC-T\#2 & $\mathrm{LC}$ & $\mathrm{T}$ & 2300 & 0.50 \\
\hline LC-T\#3 & $\mathrm{LC}$ & $\mathrm{T}$ & 5200 & 0.42 \\
\hline LC-T\#4 & $\mathrm{LC}$ & $\mathrm{T}$ & 4900 & 0.39 \\
\hline MC-L\#0 & $\mathrm{MC}$ & $\mathrm{L}$ & 0.001 & 0.62 \\
\hline MC-L\#1 & $\mathrm{MC}$ & $\mathrm{L}$ & 2800 & 0.58 \\
\hline MC-L\#2 & $\mathrm{MC}$ & $\mathrm{L}$ & 1900 & 0.38 \\
\hline MC-L\#3 & $\mathrm{MC}$ & $\mathrm{L}$ & 600 & 0.25 \\
\hline MC-L\#4 & $\mathrm{MC}$ & $\mathrm{L}$ & 0.1 & 0.62 \\
\hline MC-L\#5 & $\mathrm{MC}$ & $\mathrm{L}$ & 900 & 0.35 \\
\hline MC-L\#6 & $\mathrm{MC}$ & $\mathrm{L}$ & 2900 & 0.43 \\
\hline MC-L\#7 & $\mathrm{MC}$ & $\mathrm{L}$ & 950 & 0.36 \\
\hline MC-T\#0 & $\mathrm{MC}$ & $\mathrm{T}$ & 0.001 & 0.62 \\
\hline MC-T\#1 & $\mathrm{MC}$ & $\mathrm{T}$ & 1800 & 0.37 \\
\hline MC-T\#2 & MC & $\mathrm{T}$ & 2500 & 0.50 \\
\hline MC-T\#3 & $\mathrm{MC}$ & $\mathrm{T}$ & 1200 & 0.66 \\
\hline
\end{tabular}

were used interchangeably in the current study, with the understanding that specimens from both orientations exhibit a similar shear-stress- $v s$-strain behavior. At least two tests were performed at each strain rate for which the comparable tests were within a range of $200 / \mathrm{s}$, to confirm repeatability of the results. The only exception to this was the test performed at $5200 / \mathrm{s}$ in the LC steel, the highest-strain-rate test, where the duplicate test was performed at a rate 300/s lower. This greater difference in strain rates was due to increased variability in the output parameters with testing apparatus inputs at higher rates and loads (i.e., the same inputs produced increasingly different outputs as the strain rate and load limits of the testing apparatus were approached).

Microstructures were characterized using OM, EBSD with a PHILIPS** XL30 FEG (field emission gun)

**PHILIPS is a trademark of Philips Electronic Instruments Corp., Mahwah, NJ.

SEM, and SEM with a $\mathrm{JEOL}^{\dagger} 6300 \mathrm{FXV}$. For OM and

${ }^{\dagger} \mathrm{JEOL}$ is a trademark of Japan Electron Optics Ltd., Tokyo.

SEM, hat-shaped specimens were sectioned in half, mounted in epoxy, ground and polished to a mirror finish, and chemically etched. The LC steel was etched by swabbing with a 4 pct $\mathrm{HNO}_{3}$ in ethanol solution

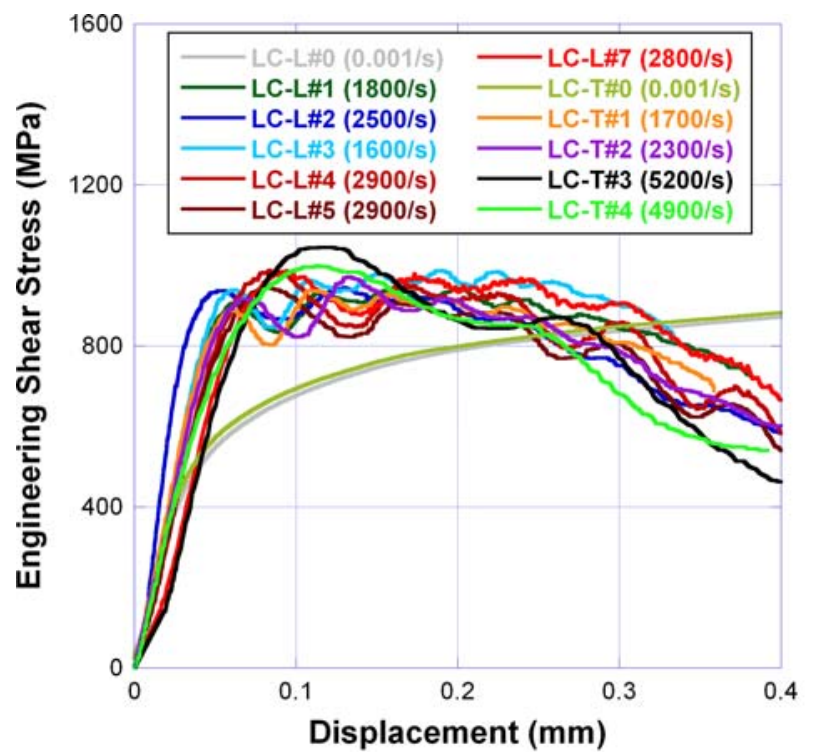

(a)

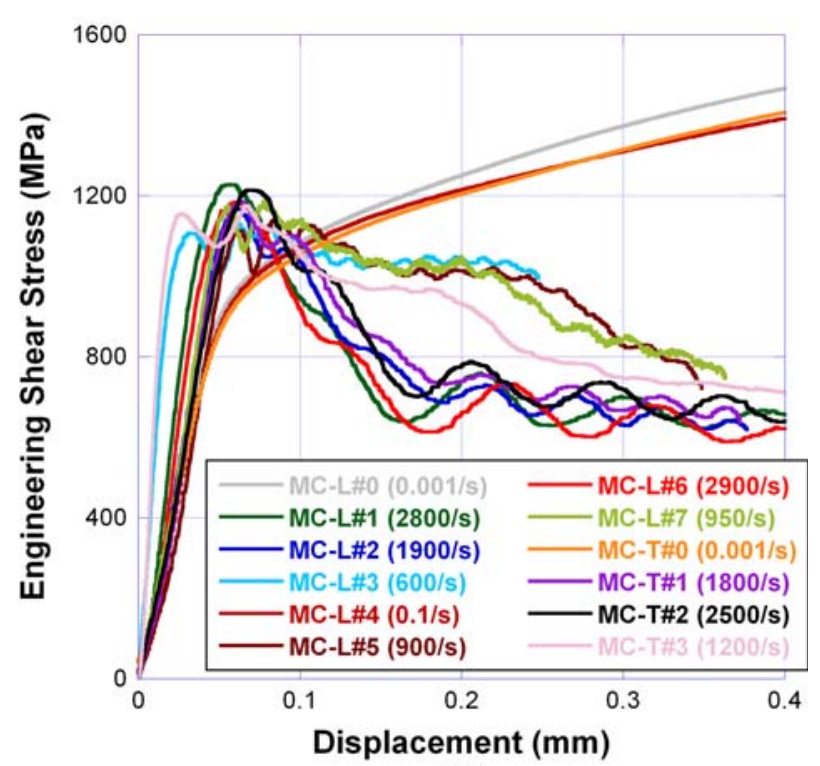

(b)

Fig. 2-All engineering-shear-stress-vs-displacement curves from Table I for (a) LC and (b) MC steel specimens. Scaling of the $y$-axis is the same in both plots, to facilitate comparison of shear behaviors of the two types of steels.

(nital). The MC steel was electrochemically etched using a 10 pct oxalic in $\mathrm{H}_{2} \mathrm{O}$ solution at room temperature and $5.7 \mathrm{~V}$. For EBSD, lightly etched specimens were given a final polish with colloidal silica on a vibratory polisher for two hours. Data were acquired and analyzed using orientation imaging microscopy (OIM) software by TexSEM Laboratories (TSL) of EDAX.

"EDAX is a tradmark of AMETEK, Inc., Materials Analysis Division, Paoli, PA.

The goal of such detailed characterization was to correlate the mechanical behavior in compression and 


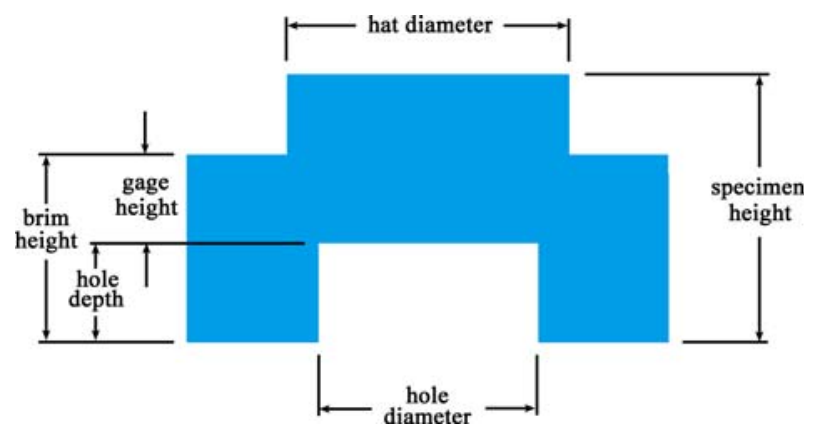

Fig. 3-Definition of dimensions used in calculating shear stresses following testing of hat-shaped specimens in SHPB apparatus.

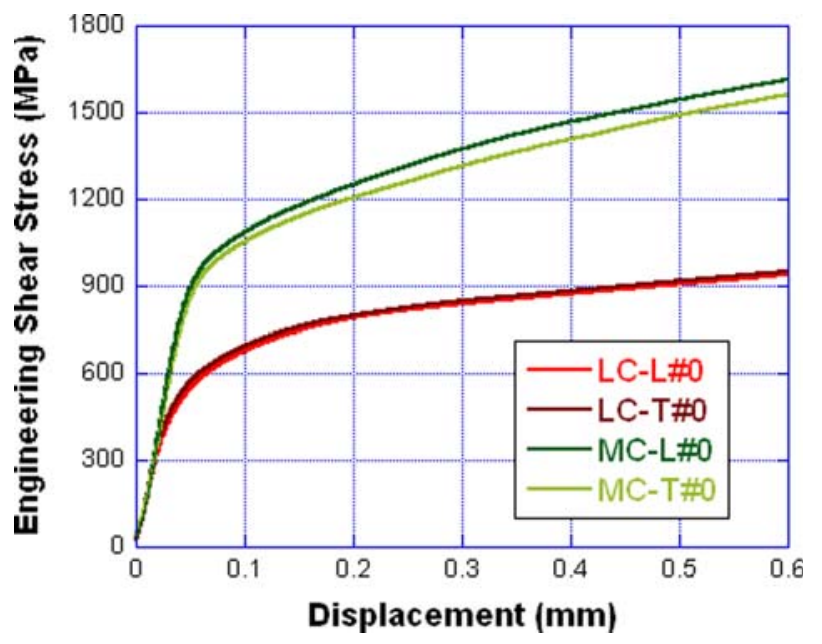

Fig. 4 -Engineering-shear-stress- vs-displacement curves from quasistatic shear tests performed at $0.001 / \mathrm{s}$ on hat-shaped specimens in a standard compression testing apparatus. The LC and MC steel specimens were sectioned in both $\mathrm{T}$ and $\mathrm{L}$ orientations, in order to correlate mechanical response with specimen orientation.

in shear to the resulting microstructures, phase distributions, and crystallographic orientations.

High-resolution imaging of the microstructures in the as-received rebar steels as well as at the edges of the shear localization zones (SLZs) and ASBs was conducted by TEM using a PHILIPS CM30 at $300 \mathrm{kV}$. Bulk TEM samples were prepared by sectioning the as-received material to the desired size using an abrasive saw, mechanically thinning to approximately $150 \mu \mathrm{m}$, and twin-jet polishing to perforation with a solution of $10 \mathrm{pct}$ perchloric acid, $20 \mathrm{pct}$ glycerol, and $70 \mathrm{pct}$ ethanol at $273 \mathrm{~K}$ and $40 \mathrm{~V}$. The TEM samples taken from the sheared regions were plucked using an $\mathrm{FEI}^{\S}$

${ }^{\S}$ FEI is a trademark of FEI Company Corporation, Hillsboro, OR.

Strata DB235 FIB/SEM.

\section{RESULTS}

Through X-ray diffraction and dark-field TEM, the microstructure of the MC steel, shown in the optical

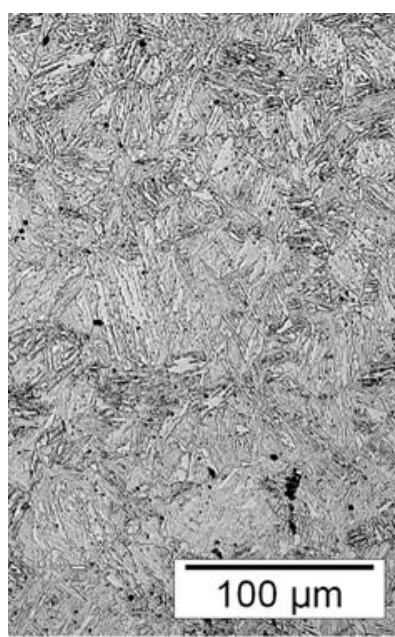

(a)

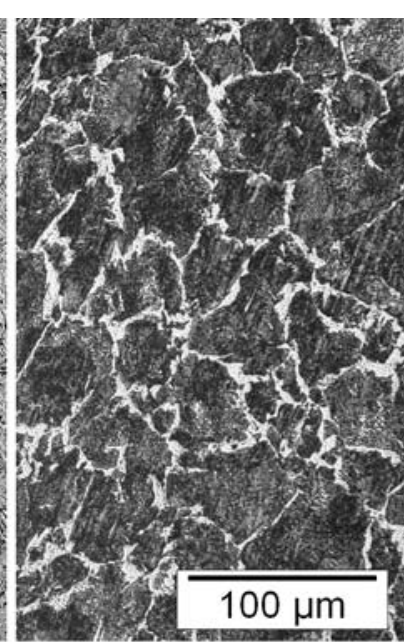

(b)
Fig. 5-(a) Microstructure, comprised predominantly of lath martensite, of as-received MC steel. (b) Microstructure of as-received LC steel, in which dark regions are pearlite colonies and light regions are ferrite between colonies.

micrograph in Figure 5(a), was found by Kusinski and Thomas $^{\left[{ }^{[0]}\right]}$ to consist of martensite laths with 5 to $10 \mathrm{vol}$ pct retained austenite between the laths. The martensite and retained austenite were determined to be of the same elemental composition, a characteristic that promotes good corrosion resistance. This high corrosion resistance was evident in the resistance of the metal to etching. Electrochemical etching was necessary, in order to provide a large enough galvanic potential to overcome the corrosion resistance resulting from the chromium and manganese alloying components and the electrically compatible phases. Only a brief chemical etch was necessary to reveal the microstructure of the LC steel, shown in Figure 5(b), which was found to consist of pearlite colonies with minor amounts of ferrite between the colonies. Due to the large galvanic potential between the ferrite and cementite as well as the absence of chromium and manganese, LC steel is much more susceptible to galvanic corrosion than the MC steel.

The results from the compression testing, shown in Figure 6, indicate that the compressive strength of the MC steel at 0.2 true strain is approximately 1.5 times greater than that of the LC steel. Yielding occurred in the LC steel at less than half the yield point of the MC steel; however, the slopes of both curves following yielding were found to be similar. Therefore, the workhardening behavior of the MC steel and LC steel were similar under quasi-static compressive loading, which indicates a similar degree of microstructural stability under this type of loading. In addition, the stability of the MC steel to a true strain of 0.2 indicates that, for the high strength exhibited, this alloy retains significant ductility.

The results from the shear tests, shown in Figure 4, that were performed at $0.001 / \mathrm{s}$ on hat-shaped specimens (LC-L\#0, LC-T\#0, MC-L\#0, and MC-T\#0) indicate, as in the compression tests, a higher strength in the $\mathrm{MC}$ steel compared to the LC steel. However, unlike in the 


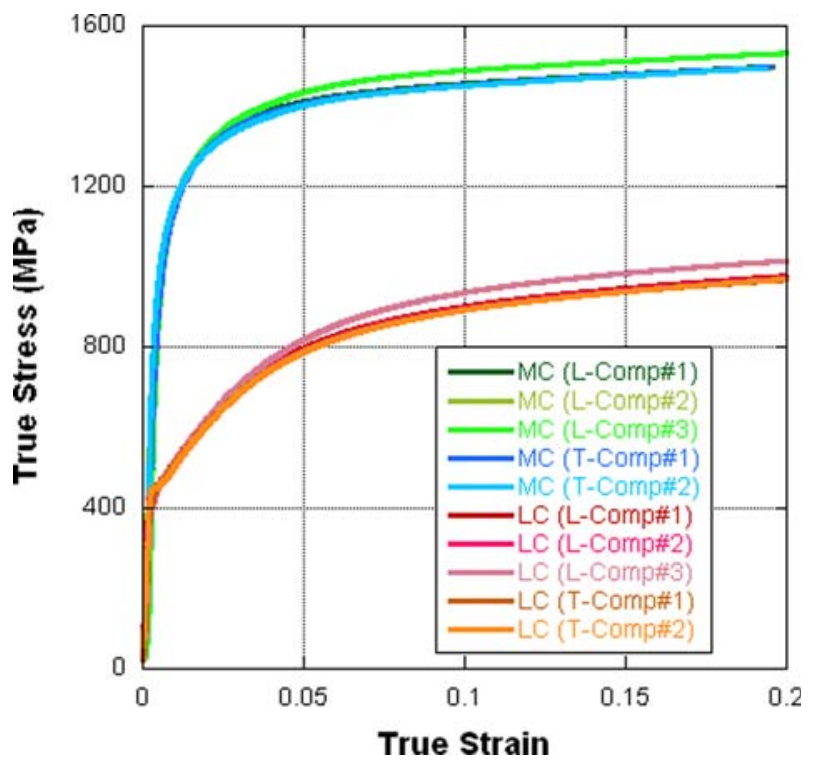

Fig. 6-Results from compression tests performed at a strain rate of $0.001 / \mathrm{s}$ on $\mathrm{T}$ and $\mathrm{L}$ specimens of LC and MC steels.

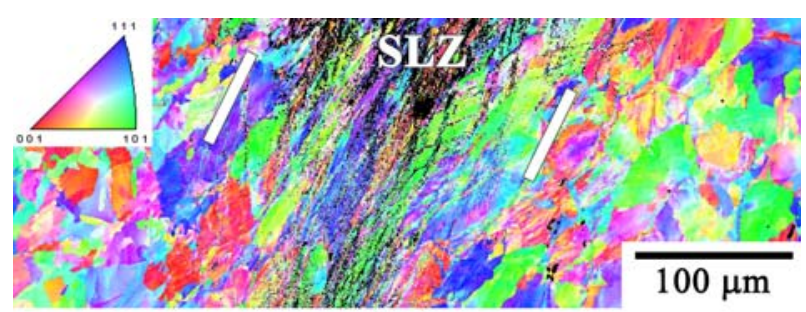

(a)

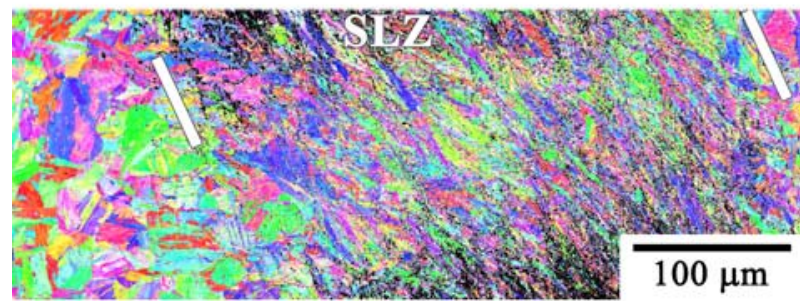

(b)

Fig. 7-EBSD maps of SLZs in hat-shaped specimens of $(a)$ LC steel and $(b)$ MC steel subjected to forced shear tests at a strain rate of $0.001 / \mathrm{s}$ to a final displacement of $0.62 \mathrm{~mm}$. The markers delineate the approximate width of SLZ in each specimen.

compression tests, the curves for the MC steel have a more positive slope than the curves for the LC steel, indicating slightly less stability in the LC steel than in the MC steel during quasi-static shear loading. This improved resistance to shear in the MC steel at quasistatic strain rates resulted in a wider region of shear localization than in the LC steel for the same amount of strain. This is illustrated by the EBSD maps shown in Figures 7(a) and (b), in which the black pixels are the result of lattice deformation sufficient to distort the backscatter diffraction patterns such that the software could not assign specific crystallographic orientations to those locations in the specimens.

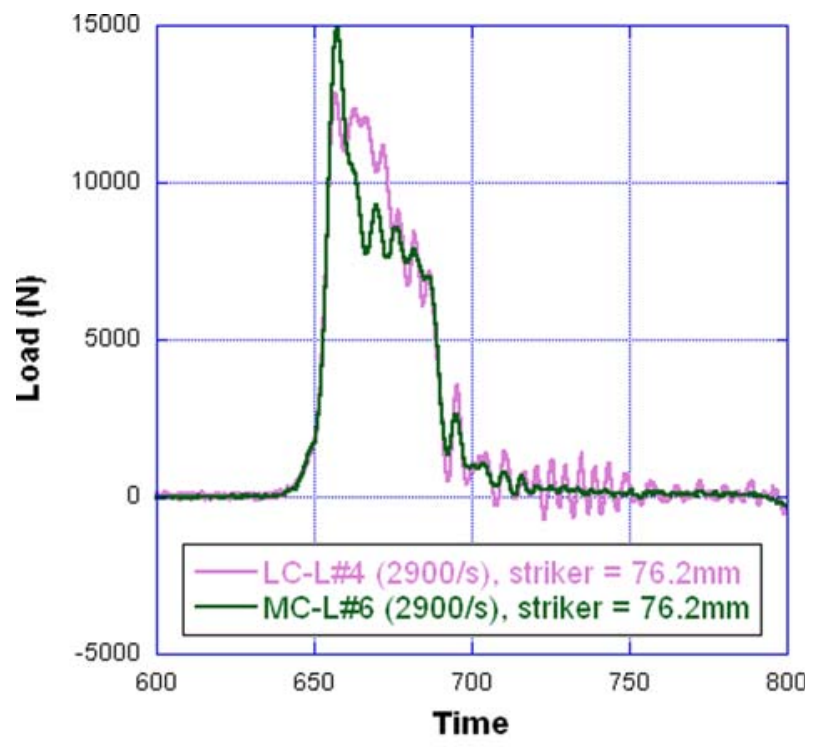

(a)

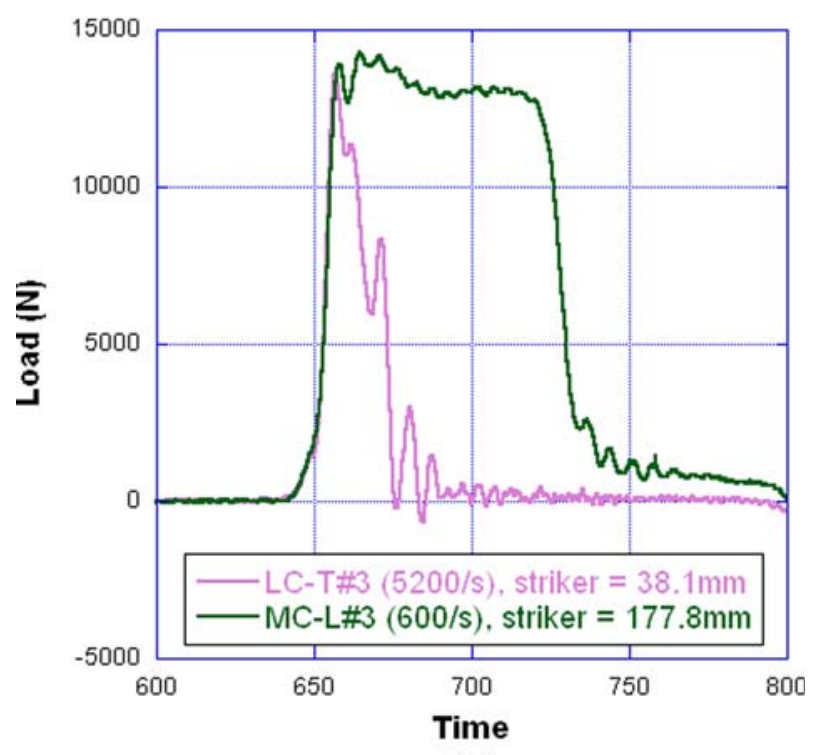

(b)

Fig. 8-Load, pulse duration, and pulse shape of dynamic shear tests performed on LC and MC steel specimens in SHPB apparatus at $(a)$ the same strain rate and pulse duration and $(b)$ a similar peak load. Time is expressed in arbitrary units.

Dynamic shear tests conducted in an SHPB apparatus indicated that, at high strain rates, the resistance to shear in the MC steel is greater than that in the LC steel under identical loads. Figure 8(a) compares the peak load of an LC steel specimen to that of an MC steel specimen tested at the same strain rate and pulse duration. Evident in this figure is a difference of nearly $2500 \mathrm{~N}$ in the peak load required to achieve similar strain rates in the two metals. Figure 8(b) compares the results from two tests with nearly the same peak load but different final displacements and drastically different strain rates and pulse durations. To achieve a reasonably short final displacement at the higher strain rate, it 
was necessary to reduce the pulse duration of the test conducted on specimen LC-T\#3. Despite the very short pulse duration, the final displacement in the LC-T\#3 was still $0.07 \mathrm{~mm}$ greater than that in the MC-L\#5.

These shear tests also showed that the strain-rate sensitivity in the MC steel is greater than that in the LC steel. This higher strain-rate sensitivity leads to a greater propensity for shear band formation at high strain rates. In the MC steel, this is evidenced by the peak and sharp drop early in the curves for the specimens tested at $1800 / \mathrm{s}$ and above. As mentioned in Section II of this report, duplicate tests were performed at each strain rate, to assure repeatability of the results. The spread in data between duplicate tests is represented by the error bars included with each curve. The lower stability of the MC steel at high strain rates compared to the LC steel can be inferred from results of the shear tests performed on both steels at equivalent strain rates. For example, both engineering-shear-stress- $v s$-displacement curves in Figure 9 are from tests performed at 2900/s; however, the curve for the MC-L\#6 test has a peak and sharp drop near the start, whereas the curve for the LC-L\#4 test has no peak.

The shear behavior of the MC steel at high strain rates also differed considerably from its behavior at lower strain rates, as shown in the engineering-shear-stress$v s$-displacement curves from tests performed at $900 / \mathrm{s}$ (MC-L\#5) and 2800/s (MC-L\#1) in Figure 10(a). The images of the ASBs produced in these tests are juxtaposed in Figure 10(b) to contrast their microstructures. At the lower strain rate, the microstructure within the ASB appears to flow in the direction of shear; at the higher strain rate, however, there is no distortion of the microstructure within the ASB in the direction of shear. Instead, at the higher rate, the original microstructure appears to sharply transition to a refined, equiaxed subgrain or grain structure within the ASB. It is interesting that the shear behavior of the MC steel specimen deformed at $900 / \mathrm{s}$ was similar to that of the LC steel specimen deformed at $2500 / \mathrm{s}$, as indicated by

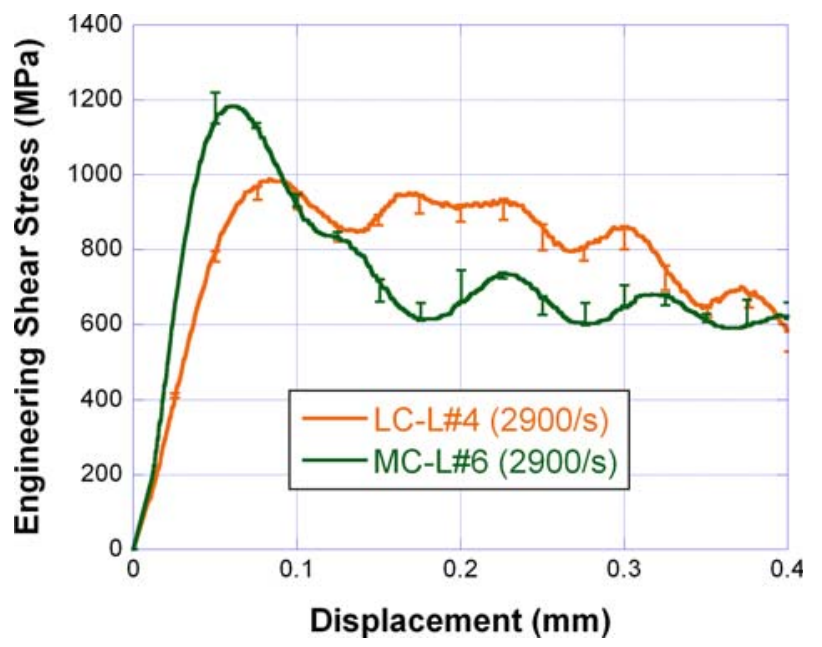

Fig. 9- Comparison of dynamic shear behavior of the LC-L\#4 and MC-L\#6, LC and MC steel specimens tested at same strain rate. the engineering-shear-stress- $v s$-displacement curves in Figure 11(a). A comparison of their sheared microstructures, shown in the optical micrographs in Figures 11(b) and (c), revealed similar characteristics.

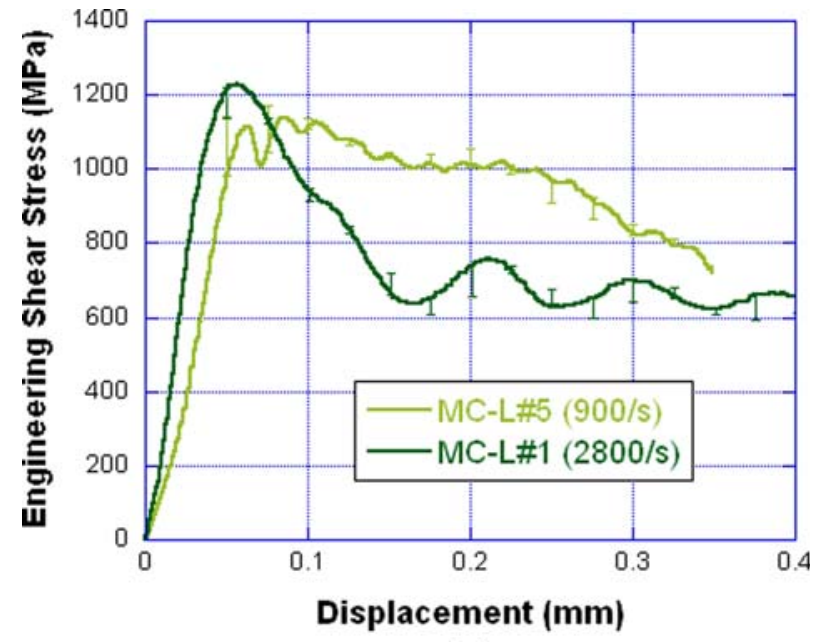

(a)

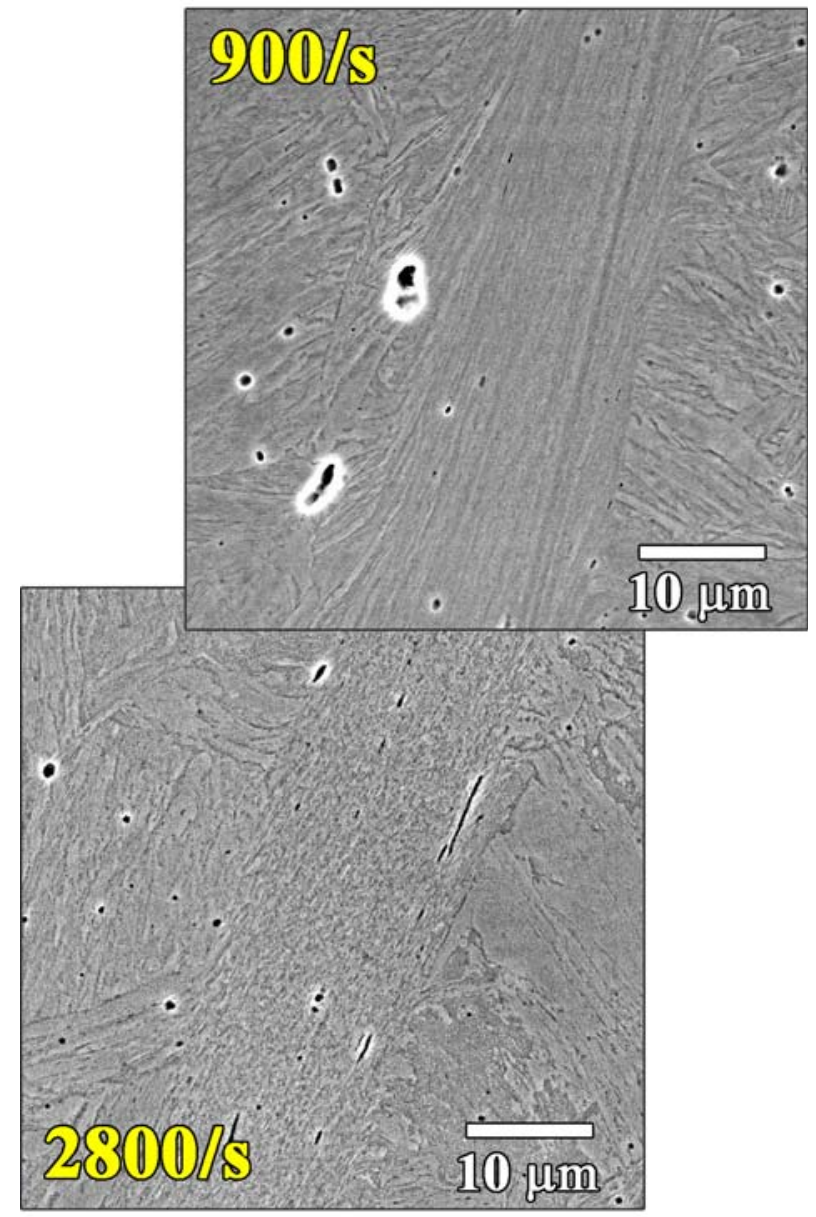

(b)

Fig. 10-(a) Engineering-shear-stress- $v s$-displacement curves illustrating variation in shear behavior with strain rate of MC steel. (b) Comparison of SEM micrographs from sheared regions of specimens tested in (a). 


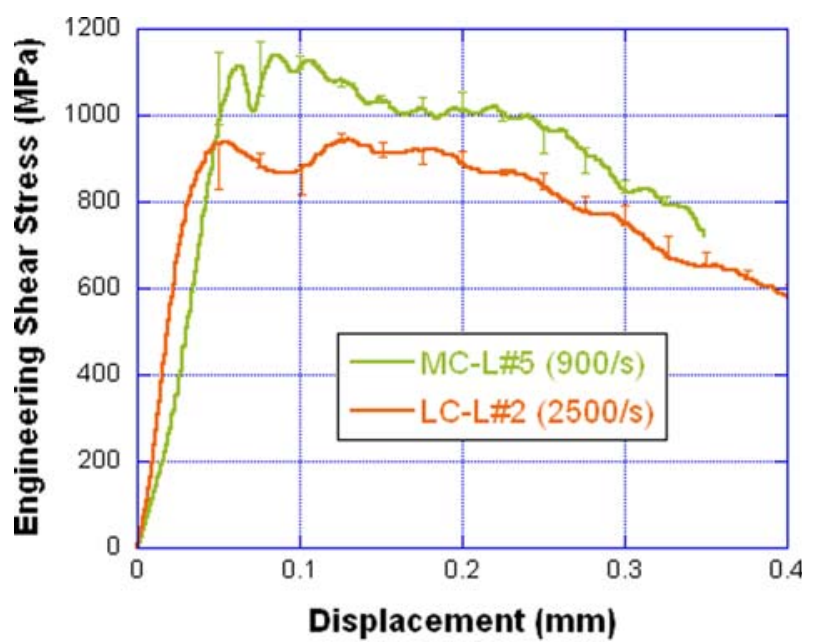

(a)

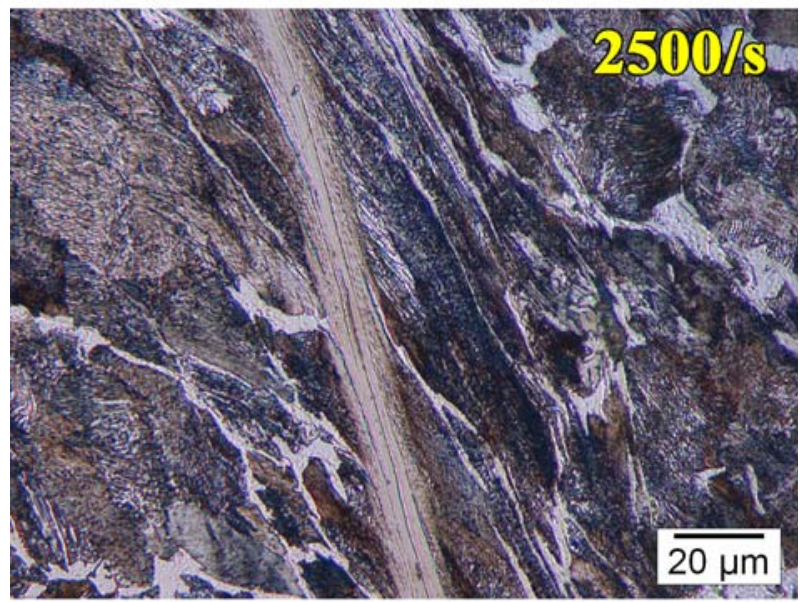

(b)

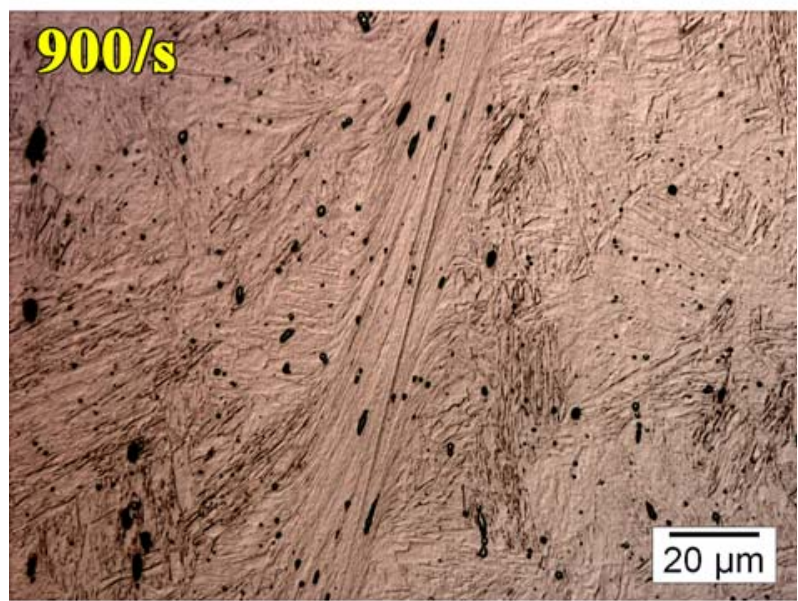

(c)

Fig. 11-(a) Engineering-shear-stress- $v s$-displacement curves showing similar shear behaviors in LC and MC steel specimens sheared at different strain rates. The OM images of SLZs in (b) LC steel specimen deformed at 2500/s, and (c) MC steel specimen deformed at $900 / \mathrm{s}$.

Dynamic shear testing of the LC steel over a range of strain rates revealed a gradual increase in the propensity for shear localization with increasing strain rate. The

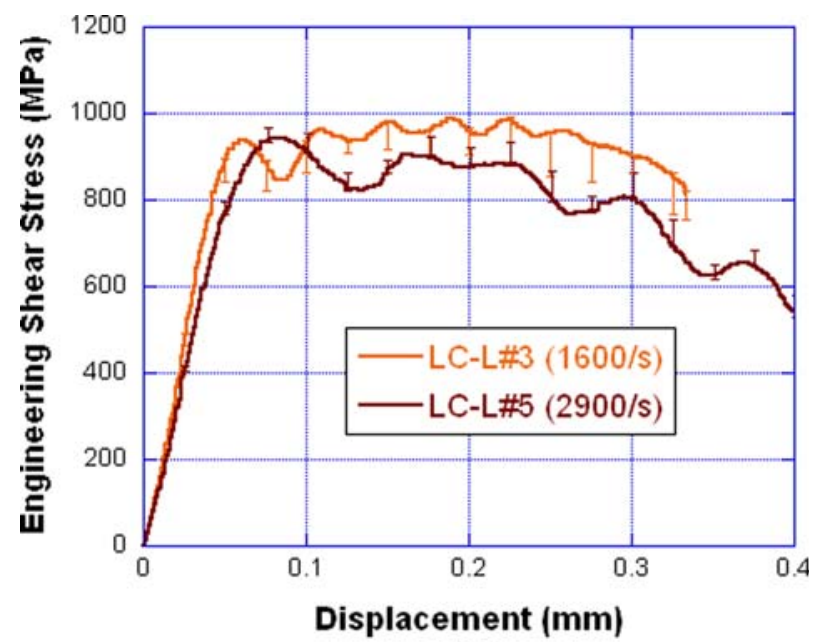

(a)

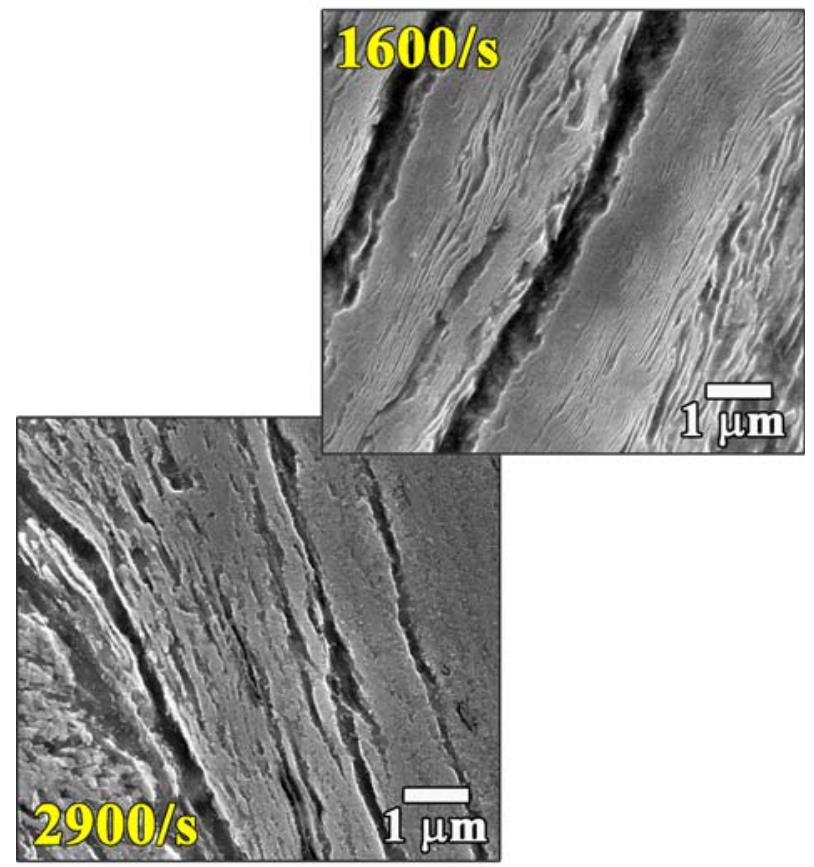

(b)

Fig. 12-(a) Engineering-shear-stress- $v s$-displacement curves showing less variation in shear behavior with strain rate in LC steel than in MC steel. (b) Comparison of SEM micrographs of sheared regions in specimens tested in (a).

flow stresses in tests performed on LC steel at 1600/s (LC-L\#3) and 2900/s (LC-L\#5), as shown in Figure 12(a), were similar, which suggests that the initial mechanisms responsible for the accommodation of shear at both strain rates were the same. However, at the higher strain rate, the microstructure destabilized at displacements above $0.2 \mathrm{~mm}$, as evidenced by the increasingly negative slope of the curve. The SEM micrographs showing the interior of the SLZs of these LC steel specimens are juxtaposed in Figure 12(b). Following the test at 1600/s, the plates of cementite were still discernable, although extensively deformed in the direction of shear, at the ASB core; following the test at 2900/s, however, the cementite and ferrite phases were no longer resolvable at 
the ASB core. It is important to note in comparisons like this, however, that the final microstructure is a complex product of the strain rate, shear strain, and starting microstructure. As such, because the final displacements of these specimens differed by $0.13 \mathrm{~mm}$, the difference in the final microstructures was a function of both the strain rate and the total strain.

In the LC steel, ASBs were produced in all SHPB tests above $2500 / \mathrm{s}$, and the core of every ASB was separated from the original microstructure by a transition zone of deformed cells and subgrains. This transition zone interfered with the measurement of the ASB width such that a relationship between the ASB width and the strain rate could not be determined. Therefore, the ASB widths in all LC steel specimens tested above $2500 / \mathrm{s}$ were considered to be similar. This was not the case for MC steel specimens tested at $1800 / \mathrm{s}$ and above. In these specimens, the ASBs were sharply defined such that the fine-grained ASB cores butted up to the original, undeformed microstructure, with no observable transition zone between them. This sharp transition enabled the measurement of ASB width as well as the correlation of the ASB width with the strain rate.

Inverse pole figure maps of the ASBs in MC steel specimens tested at three different and increasing strain rates, shown in Figures 13(a), (b), and (c), were acquired using EBSD. Of note is the narrower ASB in the specimen sheared at 1900/s (MC-L\#2), as compared with the other two. This is due to variations in both the strain rate and the final displacement. Because the final displacements in the MC-L\#5 (900/s) and the MC-L\#2 (1900/s) were similar, the narrower ASB in the MC-L\#2 must be due to the higher strain rate of the test. However, even though the strain rate of the MC-L\#1 (2800/s) test was higher than that of the MC-L\#2 test, the ASB in the MC-L\#1 was wider. This can be attributed to the 40 pct greater final displacement in the MC-L\#1 than in the MC-L\#2. The combination of these results indicates that larger strain rates produce narrower ASBs but greater final displacements (i.e., shear strains) produce wider ASBs.

The effect of the strain rate and final strain on texture within the ASBs is illustrated in Figures 14 and 15. To aid in the interpretation of these textures, the expected values for ideal shear orientations in bcc metals were identified using reports from studies involving torsion testing ${ }^{[41,42]}$ and equal channel angular extrusion. ${ }^{[25,43]}$ The reference frame of the pole figures in Figure 14 was rotated so as to correlate with the traditional frame of reference for textures in which the shear direction (SD) is along the horizontal axis and the shear plane normal (SPN) is along the vertical axis. A weak, slightly rotated simple shear texture is observed in the ASB of the MC-L\#5 in the (110) and (111) pole figures shown in Figure 14(a). In Figure 14(b), a more well-defined simple shear texture (despite the lower maximum intensity of the poles, which is an artifact of the smaller percentage of good points analyzed in the ASB of the MC-L\#2 than were analyzed in the ASB of the MC-L\#5) is evident, because the MC-L\#2 was sheared

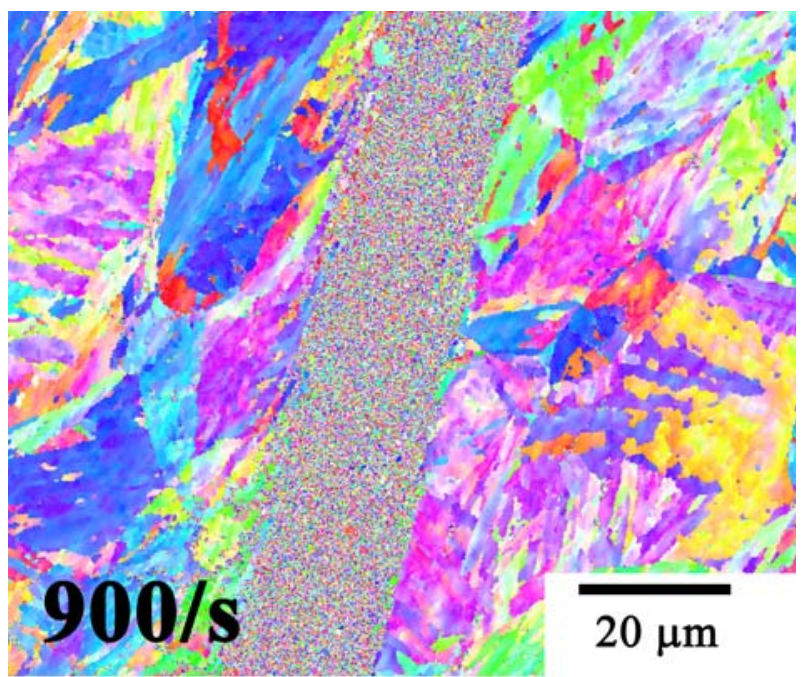

(a)

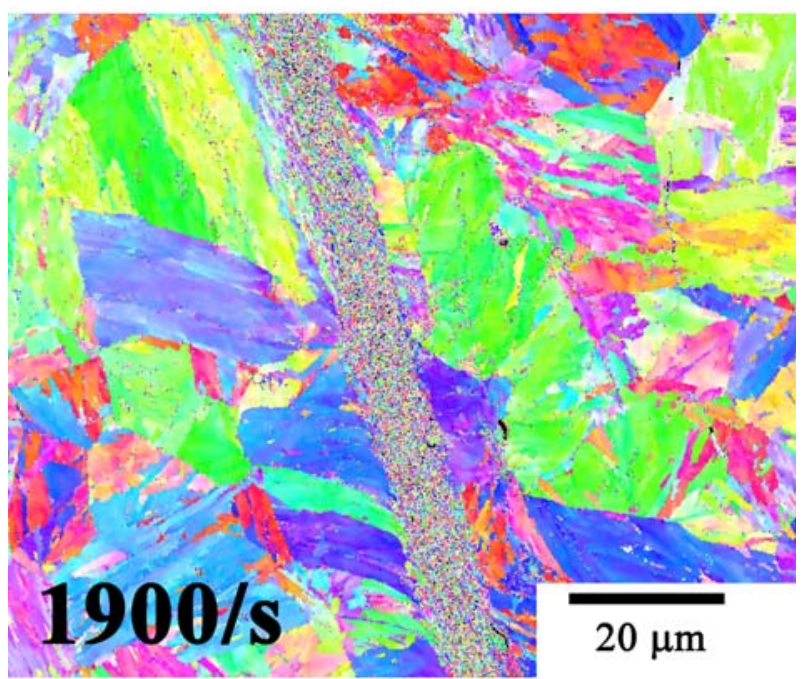

(b)

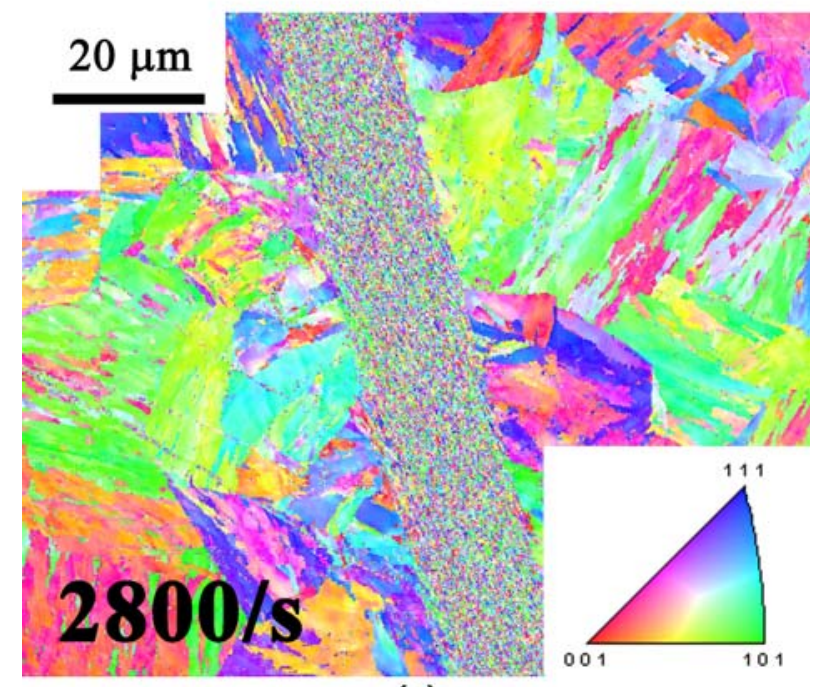

(c)

Fig. 13-Inverse pole figure maps of ASBs in MC steel specimens: (a) MC-L\#5, tested at $900 / \mathrm{s}$ to $0.35 \mathrm{~mm}$, (b) MC-L\#2, tested at $1900 / \mathrm{s}$ to $0.38 \mathrm{~mm}$, and (c) MC-L\#1, tested at $2800 / \mathrm{s}$ to $0.58 \mathrm{~mm}$. 


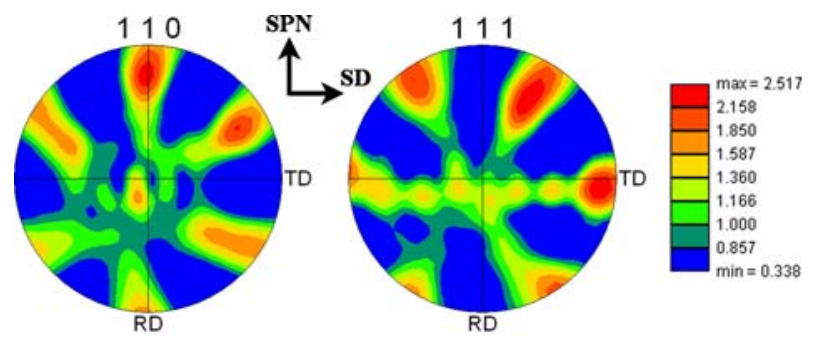

(a)

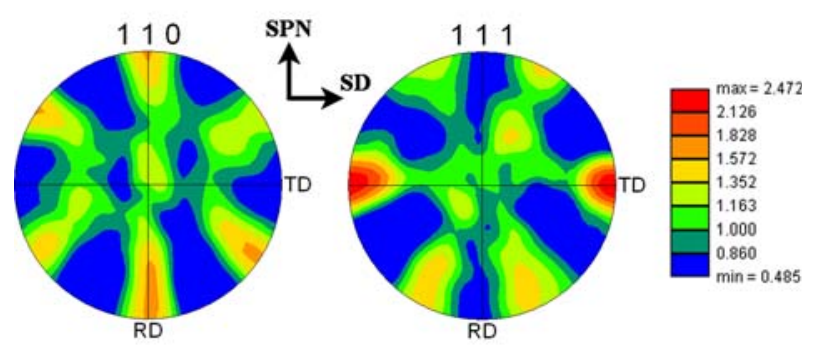

(b)

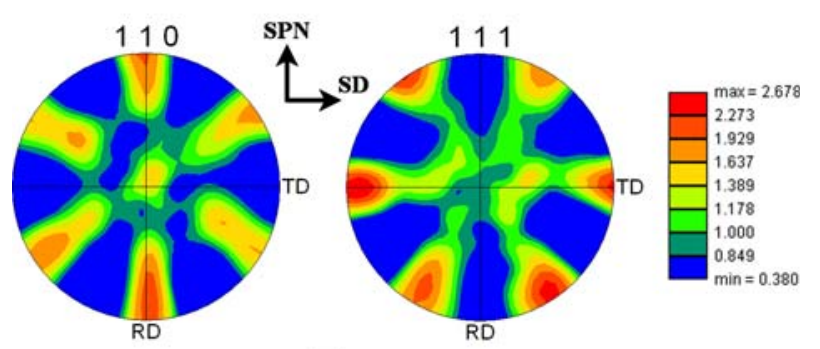

(c)

Fig. 14-Pole figures derived from ASBs mapped in Fig. 13 for MC steel specimens: (a) MC-L\#5, (b) MC-L\#2, and (c) MC-L\#1. The SPN and SD are oriented as shown.

at a higher rate to a similar displacement. In Figure 14(c), the simple shear texture is well defined, because the strain rate and final displacement of the MC-L\#1 test were greater than those of the other two SHPB tests.

To quantify these results, $\varphi_{2}=45 \mathrm{deg}$ orientation distribution function (ODF) sections, in which $\Phi, \varphi_{1}$, and $\varphi_{2}$ are Bunge Euler angles, $0 \leq \varphi_{1} \leq 360 \mathrm{deg}$, and $0 \leq \Phi \leq 90 \mathrm{deg}$, were calculated from the same data as were used to construct the pole figures in Figure 14. To simplify the identification of the preferred orientations, the reference frame was rotated to align the SD with the vertical axis and the SPN with the normal to the plane of the paper, as illustrated by the pole figures accompanying each ODF section. The preferred orientations are labeled in Figure 15(c) and correspond to the D, E, and F ideal simple shear orientations for bcc metals, where $\mathrm{D}$ orientations are the $\{112\}\langle 111\rangle$ type, E orientations are the $\{110\}\langle 111\rangle$ type, and $\mathrm{F}$ orientations are the $\{110\}\langle 001\rangle$ type. ${ }^{[41,43]}$ Although present in Figure 15(a), the simple shear texture inside the ASB was cleaner and more defined after the higher-rate test, as shown in Figure 15(b). After the highest-strain-rate test to the greatest final displacement, the simple shear texture is well defined, as shown in Figure 15(c), which indicates that the simple shear mechanism dominates the process of shear band formation and evolution. The minor rotations off the ideal orientations are the consequence of lattice rotations during the shear deformation process, which are due to some degree of freedom afforded by the distribution of shear throughout the threedimensional, shear-affected regions.

In the LC steel specimens, EBSD provided evidence (e.g., the inverse pole figure map of the ASB in the LC-L\#4 shown in Figure 16) that the microstructures within the ASBs were highly deformed but intact. The grainy appearance of the map is due to the very fine size of the grains, with diameters near the resolution limit of the instrument, in both the ferrite and cementite at the ASB core. Around the ASB core, the microstructure of the pearlite and cementite is deformed in the direction of shear. This transition zone between the unsheared pearlite/ferrite microstructure and the ASB core was observed in all LC specimens in which ASBs formed during SHPB testing, including during the LC-T\#3 test, tested at $5200 / \mathrm{s}$, the highest rate at which the data are considered reliable for this apparatus and test material.

In the MC-L\#1, tested at 2800/s, TEM imaging and selected-area diffraction confirmed the abruptness of the transition between the unsheared microstructure and the ASB core, as shown in Figure 17(a). However, at the lower rate of $900 / \mathrm{s}$, there is a transition zone of subgrain laths elongated in the direction of shear between the ASB core and the undeformed microstructure, as shown in Figure 17(b). The accompanying diffraction patterns further illustrate this refinement of the ASB microstructure, in which preferred orientations in the ring patterns acquired near the ASB edge are not observed in the ring patterns acquired near the core. This indicates a progression from relatively large, elongated subgrains to very fine, equiaxed grains as the ASB is traversed from the edge to the core. A TEM specimen, extracted across the edge of the ASB in the MC-L\#2, sheared at the intermediate rate of $1800 / \mathrm{s}$, also contained a transition zone, albeit a more narrow region, of elongated subgrain laths between the undeformed microstructure and the ASB core.

Examinations made near the edge of the ASB in the LC-L\#2, as shown in Figure 17(c), revealed a transition zone between the ASB core and the surrounding pearlite colonies. In addition to the progressive refinement of the ferrite microstructure from the outer to the inner regions of the ASB, the cementite plates in the pearlite break up in the transition zone. In the ASB core, the microstructure appears homogeneous, with no remnants of carbide plates.

\section{DISCUSSION}

In martensite, the carbon atoms occupy specific octahedral interstitial sites in a bcc lattice of iron atoms, thereby stretching one axis of the unit cell. This results in the conversion of some number of bcc cells into bct cells, the number of which depends on the amount of carbon in the steel. ${ }^{[44]}$ Because the carbon content of the MC steel used in this study is low, its crystal structure has a low degree of tetragonality. A benefit of this is 

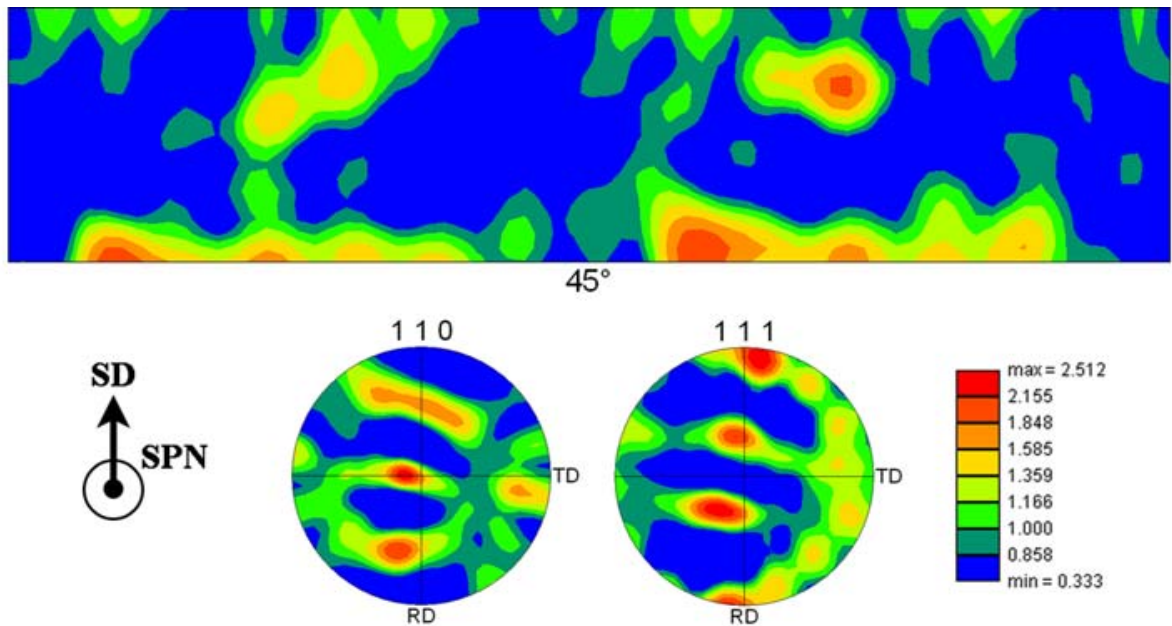

Constant Angle: $\varphi 2$

$45^{\circ}$

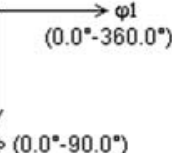

(a)
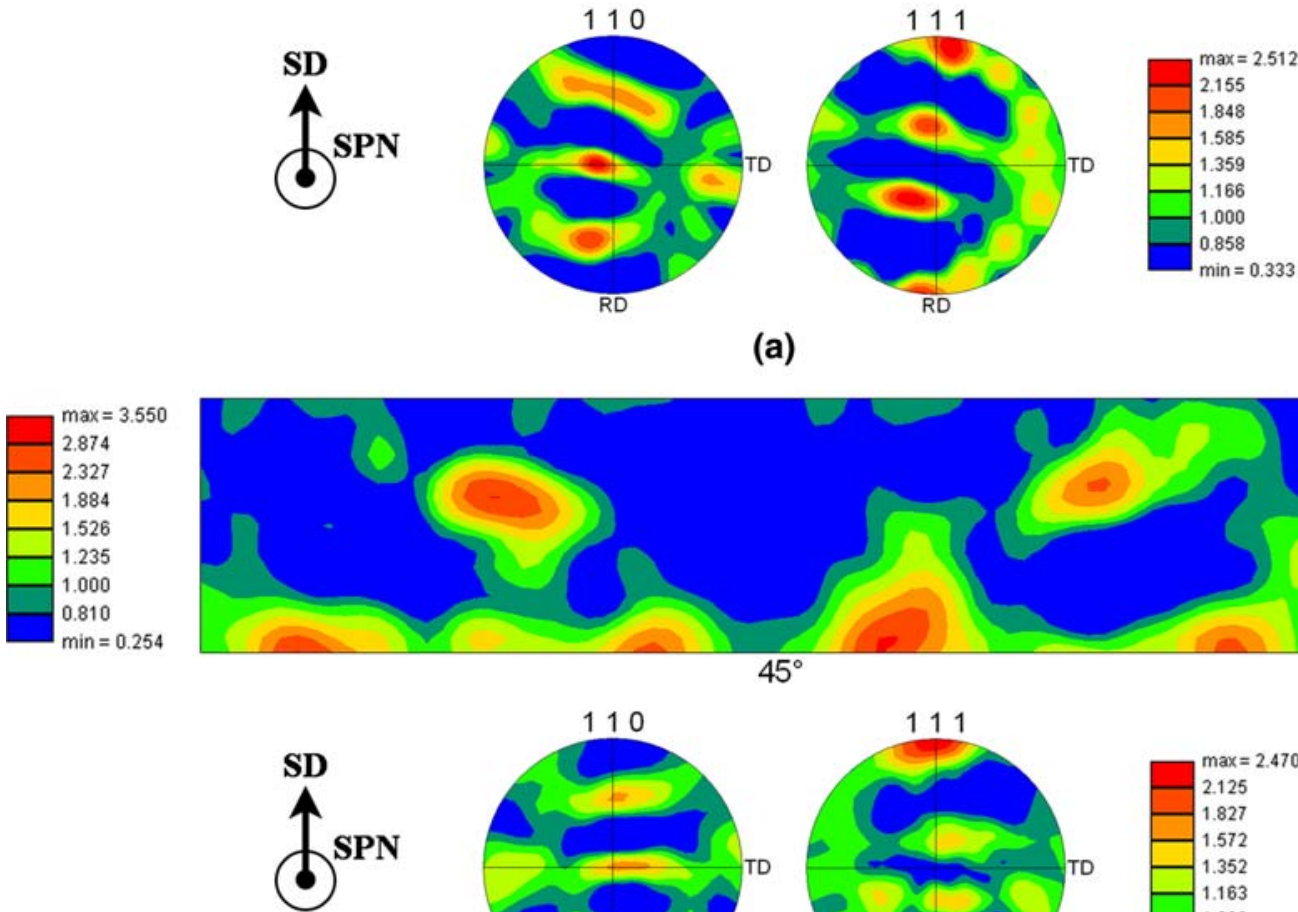

$\Phi\left(0.0^{\circ}-90.0^{\circ}\right)$ 


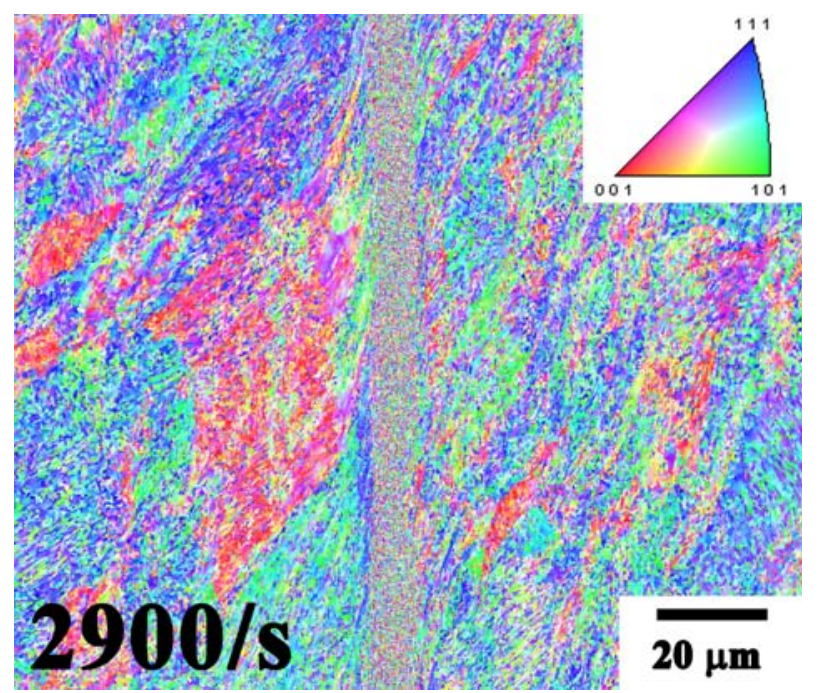

Fig. 16-Inverse pole figure map of sheared region in the LC-L\#4 deformed at 2900/s.

greater ductility than is typical of bct martensite in higher-carbon steels.

The martensitic MC steel exhibited compressive and shear strengths that were approximately $150 \mathrm{pct}$ greater than those exhibited by the LC steel specimens. At a quasi-static strain rate, the $\mathrm{MC}$ steel experienced greater work hardening than the LC steel, as shown in the engineering-shear-stress- $v s$-displacement curves in Figure 4, which indicates a more stable response to shear at very low shear strain rates. In both of these steels, shear was observed to be distributed over a broad region, as shown in the inverse pole figure maps in Figure 7, rather than in a narrow, highly localized band. This delocalization of shear, which is more pronounced in the MC steel due to its enhanced work-hardening characteristics, is due to a high resistance to low-rate shear.

At high strain rates, this higher resistance to shear in the MC steel persists as a greater resistance to shear localization under loads similar to those exerted on LC steel specimens. The higher peak in the load- $v s$-time curve for the MC steel, shown in Figure 8(a), compared to that in the LC steel curve, indicates that a larger load is required to produce the same strain rate in the MC steel as in the LC steel. At similar strain rates, as shown in the engineering-shear-stress- $v s$-displacement curves in Figure 9, these two alloys exhibit very different shear behaviors such that, at similar peak loads, as with the LC-T\#3 and MC-L\#3 in Figure 8, the strain rates in the materials may differ by an order of magnitude. Thus, even though the MC steel destabilizes at lower strain rates, greater loads are required to produce these strain rates in the MC steel than in the LC steel. However, once the load is sufficient to produce a destabilizing strain rate in the material, the MC steel is more likely to shear band than the LC steel.

During dynamic shear loading, the higher strength of the MC steel resulted in less microstructural stability compared to that of the LC steel, but not to the extent expected. This is due to a difference in the shear

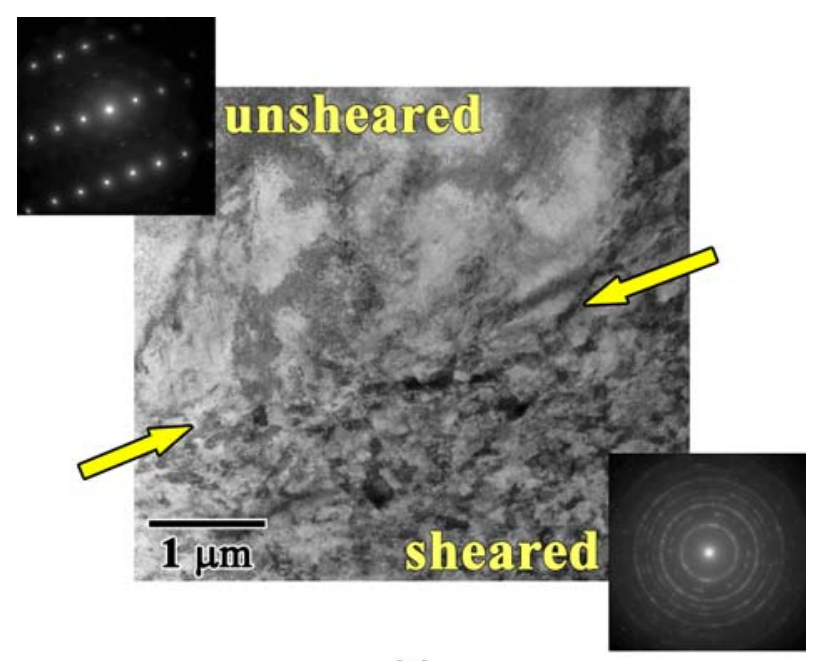

(a)

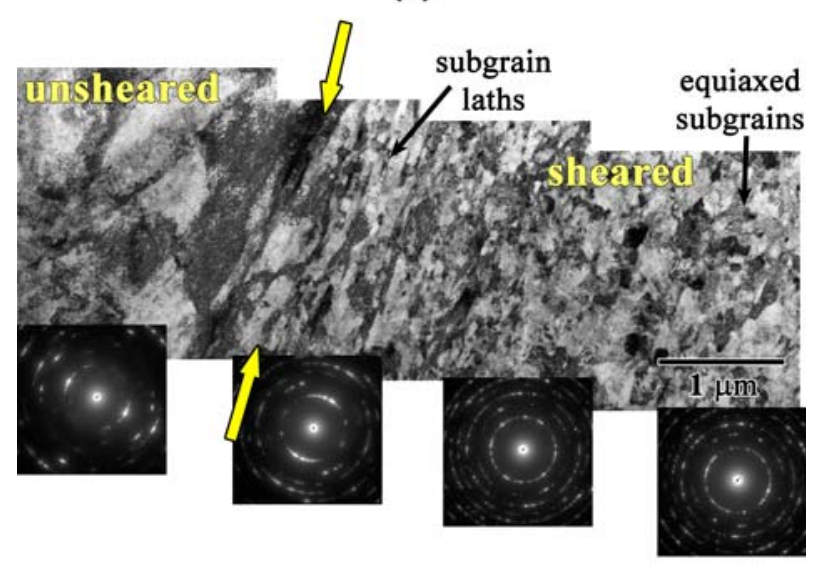

(b)

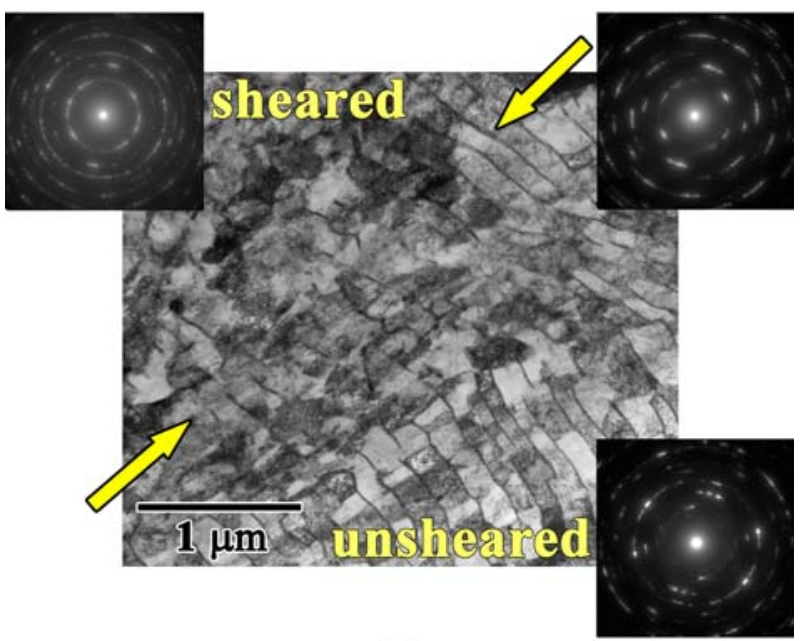

(c)

Fig. 17-The TEM micrographs of the transition between sheared and unsheared regions, i.e., edge of ASBs in (a) MC-L\#1 deformed at 2800/s, (b) MC-L\#5 deformed at 900/s, and (c) LC-L\#2 deformed at 2500/s. Arrows indicate approximate location of ASB edge.

behavior between the two materials. In comparing results from tests performed at similar strain rates (e.g., 2900/s as shown in Figure 9), it can be seen that an initial peak in the flow stress followed by a rapid drop 
occurs in the engineering-shear-stress- $v s$-displacement curve for the MC steel but not in the curve for the $\mathrm{LC}$ steel. Instead, in the LC steel, a stress plateau is observed with a gradual drop after approximately $0.3 \mathrm{~mm}$ of displacement (Figure 9). Because ASBs form in both of these materials, as evidenced by the inverse pole figure maps in Figures 13 and 16, and because a peak followed by a sharp drop in flow stress appears to correlate with the propensity of a material to form ASBs, the absence of this feature in the LC steel curve indicates that ASB formation may occur later in the dynamic shear process and possibly through mechanisms that are different in LC steel than in MC steel.

Further evidence of these differing ASB formation mechanisms was found through microscopic examination. In the MC steel deformed at 2800/s, a new, refined microstructure developed inside the ASB and minimal deformation was observed in the surrounding lath martensite, as shown in Figure 10(b). In the LC steel deformed at 2900/s, a similar structure had formed at the core of the ASB; however, the microstructure adjacent to the ASB core was severely deformed in the direction of shear, as shown in Figure 11(b). This indicates that the starting microstructure may be a factor in determining the mechanisms that operate during the formation of ASBs in these steels. It is plausible that, in the LC steel, localization occurs upon initial yield and continues into the stress plateau until, after some amount of deformation $(0.3 \mathrm{~mm}$ in the case of the LC-L\#4 in Figure 9), a shear band with a finegrained core forms.

The importance of the initial microstructure in ASB formation has been demonstrated in research on other types of steel. In a study of 1018 steel to determine the influence of shock-induced defects on dynamic shear behavior, the initial state of the microstructure was found to strongly influence its propensity to form ASBs and, hence, the mechanisms controlling ASB formation. ${ }^{[22]}$ The shocked microstructure was hardened by the introduction and storage of defects, predominantly twins and lattice dislocations and, as a result, was more susceptible to shear band formation than the as-received microstructure.

In the MC steel, at strain rates below 1000/s, the primary mechanism operating during the evolution of ASBs may be different than that dominating at higher rates. This is suggested by the differing shapes of the engineering-shear-stress- $v s$-displacement curves shown in Figure 10(a). Of particular note is the lack of an initial peak in the MC-L\#5 curve. In fact, the shape of the MC-L\#5 curve closely matches that of the LC steel tested at 2500/s, as shown in Figure 11(a), illustrating similar flow characteristics in materials with substantially different microstructures deformed at substantially different strain rates. This indicates that the predominant mechanisms of ASB formation in these two alloys at these starkly different strain rates may also be the same.

Results from post-mortem microstructural analysis of these specimens in the optical microscope (Figures 11(b) and (c)) revealed SLZs that were similar in appearance. In both specimens, most, if not all, of the microstructure in the shear bands (a white band in the LC steel and a narrow region of flow lines in the MC steel) resembles the original microstructure deformed in the direction of shear. This observation implies that, at these particular strain rates, the localization of shear in both alloys progressed in a continuous manner. However, an SEM image of the ASB in the MC-L\#1, shown in Figure 10(b), shows no residual characteristics of the original microstructure inside the ASB and no transition zone between the ASB core and the surrounding, undeformed microstructure. Because the ASB in the MC-L\#5, shown in Figure 11(c), appears to be severely deformed rather than fine grained while the entire width of the ASB in the MC-L\#1 appears to be fine grained (Figure 10(b)), the transition from shear localization to shear band formation is believed to be a continuous process that occurs between these two strain rates rather than a discontinuous change in behavior at a specific, critical strain rate. As such, the width of the ASB core and the extent of the subgrain lath transition zones depend on the total shear strain as well as on the strain rate.

As mentioned previously in this article, Hines et al. ${ }^{[32]}$ proposed a strain-induced subgrain rotation model referred to as PriSM to explain the microstructural evolution within ASBs during high-strain-rate shear deformation. In their model, applied to both copper (fcc) and tantalum (bcc), recrystallization in ASBs occurs through a mechanical rotation of subgrains rather than a diffusion-controlled mechanism. Initially, ASBs form as dislocation cell structures elongated in the direction of shear. These elongated cells subdivide into more equiaxed cells at greater strains or higher strain rates until a critical diameter has been reached. At this point, to accommodate further deformation, the cell walls narrow until the cells resemble equiaxed subgrains, and the subgrains rotate until regions of highly misoriented grains dominate the microstructure. Ordering of the boundaries and boundary dislocation annihilation occur during cooldown. Due to the rapidity of the ASB formation and evolution, the lattice dislocation density remains high, because diffusion-controlled recovery processes cannot transpire.

The transition zone of subgrain laths observed in the MC-L\#5 may be remnants of the elongated dislocations cells of the ASB when it initially formed, as described by the PriSM model. In the region of the highest shear strain (i.e., the core of the ASB) in all of the ASBs that formed in the LC and MC steel specimens, a fine distribution of equiaxed grains containing a large number of dislocations in the boundaries and interiors were observed in the ASBs. As the strain or strain rate was increased, the width of the subgrain lath region was either reduced or eliminated. This is consistent with the PriSM model, in which shear strain is accommodated by the elongated cells converting into equiaxed grains beginning in the region of highest shear strain and expanding to the full width of the ASB. The observation of a high boundary and lattice dislocation density is also consistent with the theory stated in the Hines article that the slow dislocation climb kinetics of tantalum relative to copper led to a larger lattice dislocation density. 
As with tantalum, the dislocation climb in iron is more difficult than in copper, as indicated by its higher coefficient of self-diffusion. This restricted climb leads to highly misoriented grains with boundaries that contain a high density of dislocations that are not geometrically necessary.

The TEM examinations were used to explore the microstructural changes within the ASBs of the MC steel at different strain rates, to confirm that the evolutionary path of the ASB microstructures is continuous rather than discontinuous. An image taken across the edge of the ASB in the MC-L\#1, shown in Figure 17(a), confirms the absence of a transition zone between the fine subgrains at the ASB core and the surrounding unsheared lath martensite, as was suggested by the SEM micrograph in Figure 10(b). However, an image taken across the edge of the ASB in the MC-L\#5, shown in Figure 17(b), reveals a definite transition zone, approximately $2 \mu \mathrm{m}$ in width, comprised of subgrain laths elongated in the direction of shear between a band of equiaxed subgrains at the ASB core and the unsheared martensite. Similar images taken of an ASB in the MC-L\#2, which was sheared at a rate between 900/s and $2800 / \mathrm{s}$, showed a narrower transition zone than the zone in the MC-L\#5. Because the final displacements in the MC-L\#2 and the MC-L\#5 are similar, this difference in the transition zone widths is most likely due to the difference in strain rates.

Although ASBs formed in all the MC steel specimens tested in the SHPB, ASBs were not observed in LC steel specimens deformed at rates of $1800 / \mathrm{s}$ and below. For example, an ASB did not form in the LC-L\#3, strained at $1600 / \mathrm{s}$, but was observed in the LC-L\#5, strained at $2900 /$ s. In the engineering-shear-stress- $v s$-displacement curves for these specimens, shown in Figure 12(a), a steady rise in the LC-L\#3 curve indicates a greater degree of strain hardening at lower rates. Close examination of the sheared microstructures in these specimens, shown in Figure 12(b), reveals a difference in the carbide morphology in which the cementite plates, although severely deformed along the direction of shear, still exist near the center of the sheared region in the LC-L\#3, whereas the cementite and ferrite appear to be a single phase in the core of the ASB in the LC-L\#5.

At high magnification in the TEM, a transition zone approximately $2 \mu \mathrm{m}$ in width in which the cementite plates in the pearlite have broken into pieces, as shown in Figure 17(c), is observed around the ASB core in the LC-L\#2, strained at 2500/s. Combining this observation with the comparison of the carbide morphology in the sheared regions of the LC-L\#3 and LC-L\#5 suggests that shear localization and shear band formation are stages in the same continuous process that transpires in a microstructure resistant to shear deformation. The formation of shear bands is precipitated by a high density of lattice dislocations, observed using TEM, between the carbide plates in the pearlite around the ASBs. At large deformations, the microstructure becomes increasingly unstable as more and more lattice defects are generated and subsequently trapped by cementite plates acting as barriers to defect motion. High strain rates also destabilize the microstructure by reducing the time dislocations have in which to bypass the cementite barriers in order to accommodate local shear deformation. As such, both large strains and high strain rates can lead to similar reductions in defect mobility and, hence, microstructures with a similar degree of instability.

In the MC steel, shear tests performed at three different strain rates $(900 / \mathrm{s}, 1900 / \mathrm{s}$, and $2800 / \mathrm{s})$ all resulted in the formation of ASBs. The inverse pole figure maps in Figure 13, derived from the EBSD analysis of these ASBs, revealed a sharp transition in microstructure at the ASB edges and a fine grain structure within the ASBs. The final displacements of the specimens sheared at $900 / \mathrm{s}$ and $1900 /$ s were similar, but the ASB in the specimen deformed at the higher strain rate was narrower. The final displacements of the specimens sheared at $1900 / \mathrm{s}$ and $2800 / \mathrm{s}$ were 0.38 and $0.58 \mathrm{~mm}$, respectively, resulting in a narrower ASB in the specimen sheared at the lower rate. In considering both of these results, it can be deduced that either a decreasing strain rate or an increasing total plastic strain results in an increased ASB width, in which the lower strain rate allows defects time to migrate outward to accommodate shear deformation and the larger strain forces the expansion of the ASB due to increased defect generation and storage.

The textures derived from EBSD analysis of these ASBs, shown in Figures 14 and 15, provided a quantitative representation of differences in their microstructures. The pole figures in Figure 14 were rotated to present the simple shear textures in the most familiar reference frame. The slight off-center shift of the pole figure for the MC steel specimen deformed at 900/s and the string of preferred orientations about the TD may be due to the relatively wide transition zone of lath subgrains in the ASB. These features were also present in the pole figure in Figure 15(a), which was rotated into a less familiar frame of reference to facilitate the determination of predominant crystallographic orientations.

The well-defined simple shear texture in the ASB of the specimen deformed at $2800 / \mathrm{s}$, evident in Figures 14(c) and 15(c), implies that dislocation slip along the $\{110\}$ and $\{112\}$ planes in the $\langle 111\rangle$ directions, the mechanism of simple shear in bcc metals, was the predominant mechanism operating during dynamic shear in these MC steel specimens. In the LC steel, a similar trend toward sharper shear textures at the ASB core was observed; however, because a transition zone existed between the undeformed microstructure and the fine-grained structure in the ASB cores of all of the SHPB specimens that formed an ASB, the intensities of the predominant crystallographic orientations were lower.

The engineering-shear-stress- $v s$-displacement curves for the MC steel specimens deformed at $900 / \mathrm{s}$ (MC-L\#5) and 2800/s (MC-L\#1), as shown in Figure 10(a), indicate a change in shear behavior with increasing strain rate. The rapid work softening following the initial peak in the MC-L\#1 curve is typical of a highly unstable microstructure. This peak and sharp drop in flow stress is not observed in the MC-L\#5 curve, 
indicating a greater ability of the MC steel to resist shear band formation at lower strain rates. The SEM images in Figure 10(b) show a difference in microstructure within these ASBs, in which plastic flow in the direction of shear is evident in the ASB of the MC-L\#5 but a new microstructure has formed in the ASB of the MC-L\#1. As addressed earlier, the new microstructure in the ASB of the latter specimen, also imaged with TEM, as shown in Figure 17(a), may be due to PriSM recrystallization, to reduce the energy of the severely deformed martensitic laths. The sharpening of the shear texture in the ASB, evident in the pole figures and ODF section in Figures 14(c) and 15(c), is consistent with this model, because the subgrains will rotate to higher misorientations to accommodate the increasing local strain but the direction of these rotations will be controlled by the direction of the applied shear force.

Because the shear behaviors of LC and MC steel specimens were found, in some cases, to be similar at disparate strain rates, comparisons were made between the microstructures of the ASBs in the LC steel and MC steel specimens that exhibited similar shear behavior and the specimens tested at similar strain rates. This was possible at lower strain rates, such as $900 / \mathrm{s}$ in the MC steel and $2500 / \mathrm{s}$ in the LC steel, in which the shear behavior and resulting ASB microstructures were comparable. At higher strain rates in the MC steel, such as $2800 / \mathrm{s}$, the fine-grained core resembled the fine-grained core of the LC steel specimens tested at $2500 / \mathrm{s}$ up to $5200 / \mathrm{s}$, but the transition between the ASB core and surrounding microstructures differed. This indicates that the same mechanisms are most likely operating during the development of the ASBs in both the LC and MC steels, but the rate of this development is much slower in the LC steel than in the MC steel.

\section{CONCLUSIONS}

The shear deformation behavior of two types of rebar steels, standard grade $420 \mathrm{LC}$ steel and MMFX-9Cr MC steel, was investigated as a function of the strain rate and total plastic strain. Comparing microstructural characteristics with the mechanical responses of 24 specimens yielded the following conclusions.

1. The MC steel resisted shear deformation more effectively than the LC steel when subjected to quasi-static shear loading. At quasi-static strain rates, the region of the gage section affected by the imposed shear deformation was wider in the MC steel than in the LC steel.

2. The MC steel exhibited a higher strain-rate sensitivity than the LC steel but also a greater resistance to shear localization vs load, due to its greater yield strength, i.e., the load required at all strain rates to induce shear localization was larger in the MC steel than in the LC steel.

3. Larger strain rates produce narrower ASBs in the MC steel, whereas larger final displacements produce wider ASBs. The widths of the ASBs in the
LC steel are not as sharply defined as those in the MC steel; however, at the strain rates at which ASBs were observed to form in the LC steel, i.e., at and above $2500 / \mathrm{s}$, the widths were similar.

4. The textures within the ASBs of the MC steel specimens deformed in the SHPB resembled those of simple shear, in which the intensities of the ideal orientations increased with an increasing strain rate. The simple shear texture was well defined in the MC steel SHPB specimen tested at 2800/s. A similar trend was observed in the LC steel.

5. A shift from shear localization at lower strain rates to shear band formation at higher strain rates occurred during a series of SHPB tests in the MC steel. In a specimen sheared at $900 / \mathrm{s}$, a transition zone of elongated subgrain laths was observed, which indicates that the evolution of the ASB microstructure in this steel is a continuous process. Microstructural examination of a specimen tested at 1900/s revealed a similar but narrower subgrain lath transition zone. In a specimen sheared at $2800 / \mathrm{s}$, no transition zone was observed.

6. No sharp transition such as that observed at $2800 / \mathrm{s}$ in the MC steel was observed in the LC steel, up to a strain rate of 5200/s. A sharp drop in the shearstress- $v s$-displacement curves after the initial peak for the MC steel correlates with a very narrow or missing transition zone between the undeformed microstructure and the fine, equiaxed grains in the ASB core. The lack of this sharp drop in all tests on the LC steel and in the tests below $1800 / \mathrm{s}$ on the MC steel correlated with the presence of a substantial transition zone. This indicates that the ASB formation and evolution mechanisms in the LC and MC steels are the same, but the processes are slower in the LC steel and require a higher strain rate to activate.

7. Microstructural observations made within the ASBs following SHPB tests are consistent with the PriSM mechanism for recrystallization controlling the transformation of the highly deformed microstructure in the localized shear region to a band of fine, equiaxed grains containing a high density of boundary and lattice dislocations.

\section{ACKNOWLEDGMENTS}

This work has been performed under the auspices of the United States Department of Energy. The authors thank the MMFX Technologies Corporation for its assistance in this research and for providing the material for testing. The authors also thank P.A. Papin for her assistance in TEM specimen extraction using FIB machining and R.M. Dickerson and R.J. McCabe for their assistance with the electron microscopy. Special appreciation is offered to J.F. Bingert for assisting in the interpretation and representation of the textures in this article. 


\section{OPEN ACCESS}

This article is distributed under the terms of the Creative Commons Attribution Noncommercial License which permits any noncommercial use, distribution, and reproduction in any medium, provided the original author(s) and source are credited.

\section{REFERENCES}

1. "ASTM A615/A615M-07 Standard Specification for Deformed and Plain Carbon-Steel Bars for Concrete Reinforcement," ASTM International, West Conshohocken, PA, 2007, vol. 01.04, pp. 1-6.

2. "ASTM A955/A 955M-07a Standard Specification for Deformed and Plain Stainless- Steel Bars for Concrete Reinforcement," Annual Book of ASTM Standards, ASTM International, West Conshohocken, PA, 2007, vol. 01.04, pp. 1-11.

3. "ASTM A775/A775M- 07 ASTM A775/A775M-07 Standard Specification for Epoxy-Coated Steel Reinforcing Bars," Annual Book of ASTM Standards, ASTM International, West Conshohocken, PA, 2007, pp. 1-10.

4. M. Arockiasamy, P.V. Vijay, B. Benmokrane, and M. Shahawy: Final Report for NCHRP Project 10-55, Florida Atlantic University, 2003, pp. 1-12.

5. G.J. Kusinski: MMFX Technologies Corporation, Irvine, CA, private communication, 2007.

6. G.G. Clemena and Y.P. Virmani: Concrete Int., 2004, vol. 26 (11), pp. $39-49$

7. G.J. Kusinski, D.G. Pollack, and G. Thomas: U.S. Patent WO/2003/052152, International Bureau of WIPO, USPTO, 2006, pp. $1-11$.

8. "ASTM A1035/A1035-07 Standard Specification for Deformed and Plain, Low-Carbon, Chromium, Steel Bars for Concrete Reinforcement," Annual Book of ASTM Standards, ASTM International, West Conshohocken, PA, 2007.

9. R. El-Hacha and S.H. Rizkalla: NCSU-CFL Report No. 02-04, Constructed Facilities Laboratory of NCSU, 2004.

10. Y.B. Xu, Y.L. Bai, Q. Xue, and L.T. Shen: Acta Mater., 1996, vol. 44 (5), pp. 1917-26.

11. A. Bussiba, H. Alush, M. Kupiec, and Y. Katz: in Structures under Shock and Impact $V$, N. Jones, D.G. Talaslidis, C.A. Brebbia, and G.D. Manolis, eds., Computational Mechanics Publications Ltd., Thessaloniki, Greece, 1998, pp. 559-68.

12. J.A. Hines and K.S. Vecchio: Acta Mater., 1997, vol. 45 (2), pp. 635-49.

13. R.W. Armstrong and F.J. Zerilli: Mech. Mater., 1994, vol. 17 (2-3), pp. 319-27.

14. S.A. Manion and T.A.C. Stock: Int. J. Fract. Mech., 1970, vol. 6 (1), pp. 106-07.

15. M.A. Meyers and C.L. Wittman: Metall. Trans. A, 1990, vol. 21A, pp. 3153-64.

16. A.L. Wingrove: Metall. Trans., 1973, vol. 4, pp. 1829-33.
17. C.L. Wittman, M.A. Meyers, and H.-R. Pak: Metall. Trans. A, 1990, vol. 21A, pp. 707-16.

18. R.L. Woodward and R.L. Aghan: Mater. Forum, 1978, vol. 1 (4), pp. $180-84$.

19. J.F.C. Lins, H.R.Z. Sandim, K.S. Vecchio, and D. Raabe: Mater. Sci. Forum, 2005, vols. 495-497, pp. 393-98.

20. M.A. Meyers, Y.B. Xu, Q. Xue, M.T. Pérez-Prado, and T.R. McNelley: Acta Mater., 2003, vol. 51 (5), pp. 1307-25.

21. J.F.C. Lins, H.R.Z. Sandim, H.-J. Kestenback, D. Raabe, and K.S. Vecchio: Mater. Sci. Eng., A, 2007, vol. 457, pp. 205-18.

22. L.M. Dougherty, E.K. Cerreta, E.A. Pfeif, C.P. Trujillo, and G.T. Gray, III: Acta Mater., 2007, vol. 55 (18), pp. 6356-64.

23. E. El-Danaf, S.R. Kalidindi, R.D. Doherty, and C. Necker: Acta Mater., 2000, vol. 48 (10), pp. 2665-73.

24. A.P. Zhilyaev, T.R. McNelley, and T.G. Langdon: J. Mater. Sci., 2007, vol. 42 (5), pp. 1517-28.

25. S. Li, A.A. Gazder, I.J. Beyerlein, E.V. Pereloma, and C.H.J. Davies: Acta Mater., 2006, vol. 43, pp. 1087-1100.

26. A. Castellero, S.J. Lloyd, S.V. Madge, Zs. Kovacs, J.F. Loffler, M. Baricco, and A.L. Greer: J. Alloys Compd., 2007, vols. 434-435, pp. $48-51$.

27. K.M. Cho, S. Lee, S.R. Nutt, and J. Duffy: Acta Metall. Mater., 1993, vol. 41 (3), pp. 923-32.

28. C.O. Mgbokwere, S.R. Nutt, and J. Duffy: Mech. Mater., 1994, vol. 17 (2-3), pp. 97-110.

29. M.A. Meyers and H.-R. Pak: Acta Metall., 1986, vol. 34 (12), pp. 2493-99.

30. Q. Xue, E.K. Cerreta, and G.T. Gray, III: Acta Mater., 2007, vol. 55 , pp. 691-704.

31. C.G. Lee, W.J. Park, S. Lee, and K.S. Shin: Metall. Mater. Trans. A, 1998, vol. 29A, pp. 477-83.

32. J.A. Hines, K.S. Vecchio, and S. Ahzi: Metall. Mater. Trans. A, 1998, vol. 29A, pp. 191-203.

33. D.R. Lesuer, C.K. Syn, and O.D. Sherby: Mater. Sci. Eng., A, 2005, vols. 410-411, pp. 222-25.

34. R.C. Glenn and W.C. Leslie: Metall. Trans., 1971, vol. 2, pp. $2945-47$

35. E.V. Tatyanin, N.F. Borovikov, V.G. Kurdyumov, and V.L. Indendom: Phys. Solid State, 1997, vol. 39 (7), pp. 1097-99.

36. J.H. Giovanola: Mech. Mater., 1988, vol. 7 (1), pp. 73-87.

37. Q. Xue and G.T. Gray III: Metall. Mater. Trans. A, 2006, vol. 37A, pp. 2447-58.

38. Q. Xue and G.T. Gray III: Metall. Mater. Trans. A, 2006, vol. 37A, pp. 2435-46.

39. C. Hill, C.C. Chiaw, and I.E. Harik: Report No. KYSPR 00-215, KTC, University of Kentucky, Lexington, KY, 2003, pp. 1-25.

40. G.J. Kusinski and G. Thomas: Proc. 1st Int. Conf. Super High Strength Steels, AIM, Rome, Italy, 2005, CD.

41. J. Baczynski and J.J. Jonas: Acta Mater., 1996, vol. 44 (11), pp. 4273-88.

42. F. Montheillet, M. Cohen, and J.J. Jonas: Acta Metall., 1984, vol. 32 (11), pp. 2077-89.

43. S. Li, I.J. Beyerlein, and M.A. Bourke: Mater. Sci. Eng., A, 2005, vol. 394 (1-2), pp. 66-77.

44. G. Krauss: Steels: Processing, Structure, and Performance, ASM INTERNATIONAL, Materials Park, OH, 2005, pp. 55-59. 